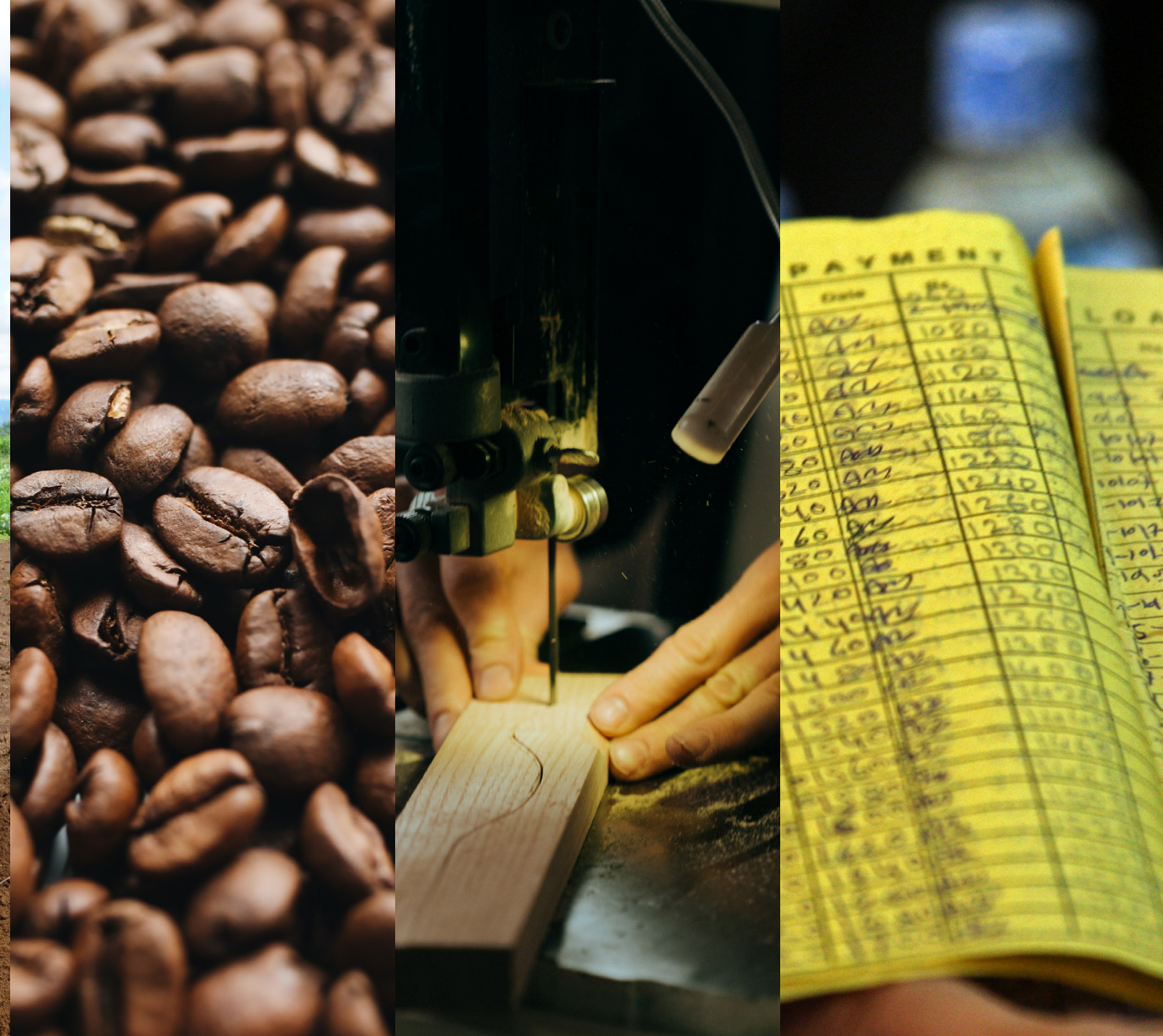

\title{
Assessment of Secondary Markets for Movable Assets in the Jamaica Manufacturing Sector
}

October, 2020

With the Support of

\section{Government Gouvernement of Canada du Canada}

C. Schweizerische Eidgenossenschaft Confédération suisse Confederazione Svizzera Confederaziun svizra

Swiss Confederation

Federal Department of Economic Affairs, Education and Research EAER

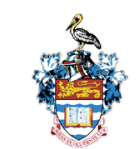

UWI

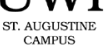

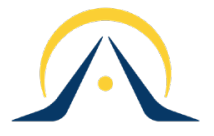

ARTHUR LOK JACK GLOBAL SCHOOL OF BUSINESS
MINISTRY OF INDUSTRY, COMMERCE agriCULTURE \& FISHERIES 
1818 H Street NW

Washington, DC 20433

Telephone: $202-473-1000$

Internet: www.worldbank.org

All rights reserved.

This work is a product of the staff and external authors of the World Bank Group. The World Bank Group refers to the member institutions of the World Bank Group: The World Bank (International Bank for Reconstruction and Development); International Finance Corporation (IFC); and Multilateral Investment Guarantee Agency (MIGA), which are separate and distinct legal entities each organized under its respective Articles of Agreement. We encourage use for educational and noncommercial purposes.

The findings, interpretations, and conclusions expressed in this work do not necessarily reflect the views of the Directors or Executive Directors of the respective institutions of the World Bank Group or thegovernments they represent. The World Bank Group does not guarantee the accuracy of the dataincluded in this work.

\section{Rights and Permissions}

The material in this publication is copyrighted. Copying and/or transmitting portions or all of this work without permission may be a violation of applicable law. The World Bank encourages dissemination of its work and will normally grant permission to reproduce portions of the work promptly.

All queries on rights and licenses, including subsidiary rights, should be addressed to the Office of the Publisher, The World Bank Group, 1818 H Street NW, Washington, DC 20433, USA; fax: 202-522-2422; e-mail: pubrights@worldbank.org. 


\section{ACKNOWLEDGMENTS}

The publication of this study was made possible through the generous support of the Government of Canada and the Swiss State Secretariat for Economic Affairs (SECO). The study was led by a team composed of Pratibha Chhabra (Financial Sector Specialist) and Lillian Thyssen (Financial Sector Specialist) and prepared by the Arthur Lok Jack Global School of Business with support from within the World Bank Group under the guidance of Mahesh Uttamchandani, Damien Shiels, and Alejandro Alvarez de la Campa (Practice Managers). This publication benefitted immensely from the participation, guidance, and insights of other experts from the Secured Transactions and Asset-Based Lending Team (John M. Wilson, Elaine MacEachern, and Luz Maria Salamina) and from the input of Nelissa Hines (Analyst, World Bank Group); Karen Hylton (Small Business Financing Specialist) and Oral Shaw (Principal Director), MSME Division, Ministry of Industry, Commerce, Agriculture and Fisheries; and Imega Breese McNab (Executive Director), Jamaica Manufacturers and Exporters Association.

The Arthur Lok Jack team that composed the report included Dr. Richard Ramsawak (Team Lead/Strategy and Competitiveness Expert), Dr. Miguel Dindial (International Business and Strategy Expert), Mr. Charles Maynard (Financial Expert), Ms. T’Nasha La Roche (Project Manager), Ms. Sade Lazzar (Researcher), Ms. Rochelle Stafford (Researcher), Mr. Etel Williams (Researcher), and Ms. Amrita Roodal (Project Assistant). The team would like to thank Nitin Kapoor from Vertical Accord for the design of the report.

With the Support of

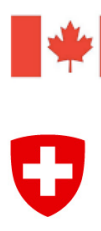

\section{Government Gouvernement of Canada du Canada}

Schweizerische Eidgenossenschaft

Confédération suisse

Confederazione Svizzera

Confederaziun svizra

Swiss Confederation

Federal Department of Economic Affairs, Education and Research EAER

State Secretariat for Economic Affairs SECO

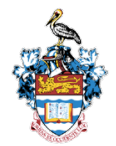

UWI

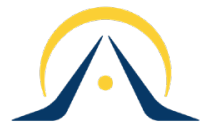

ARTHUR LOK JACK GLOBAL SCHOOL OF BUSINESS INNOVATUS ARS DUCENDI

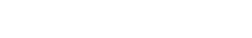




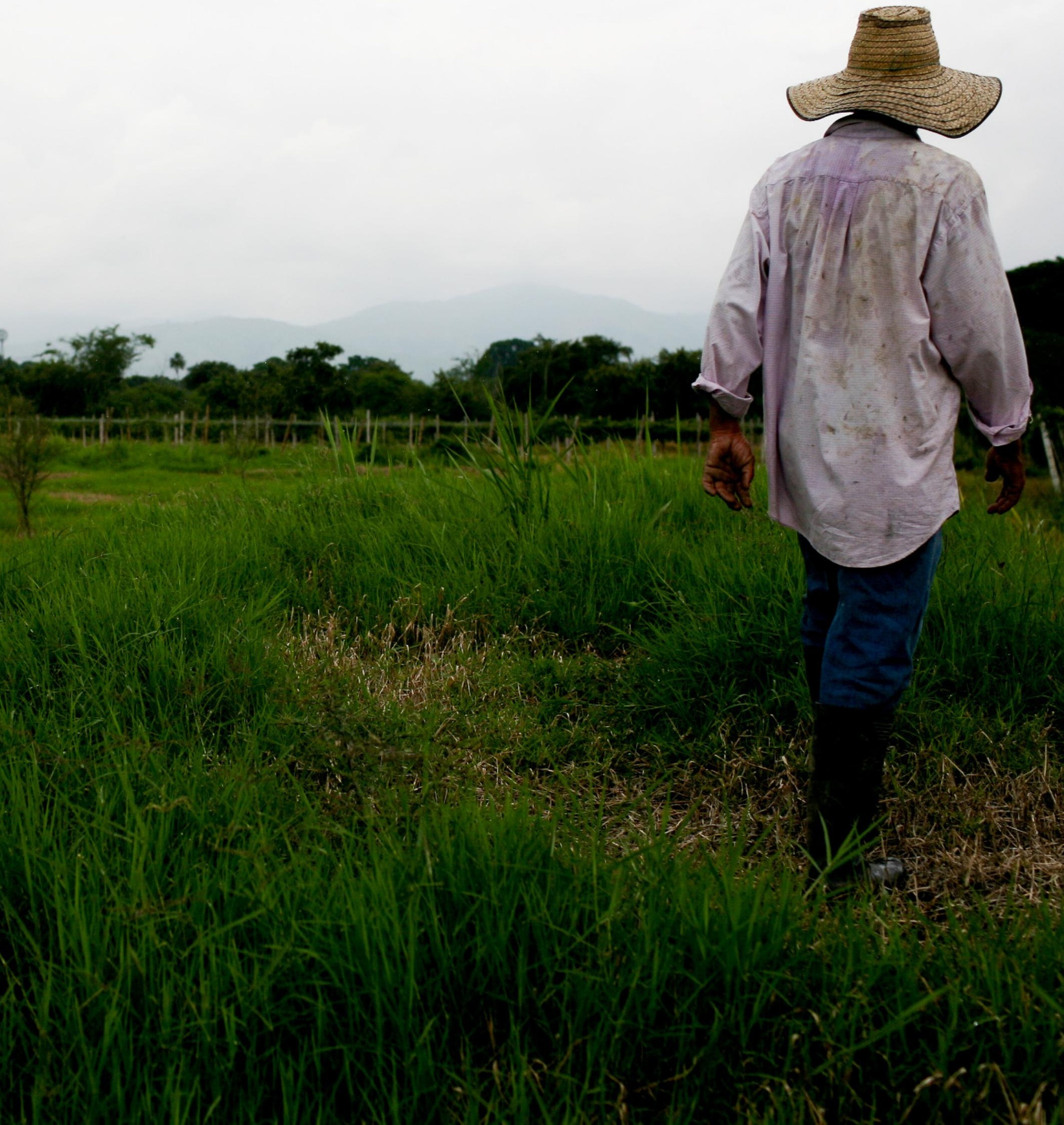




\section{LIST OF ACRONYMS}

$\begin{array}{ll}\text { ABL } & \text { Asset-based lending } \\ \text { BOJ } & \text { Bank of Jamaica } \\ \text { DBJ } & \text { Development Bank of Jamaica } \\ \text { JAS } & \text { Jamaica Agricultural Society } \\ \text { JMEA } & \text { Jamaica Manufacturers and Exporters Association } \\ \text { MABL } & \text { Movable Asset-based Lending } \\ \text { MICAF } & \text { Ministry of Industry, Commerce, Agriculture and Fisheries } \\ \text { MSME } & \text { Micro, Small, and Medium enterprise } \\ \text { NSIPPR } & \text { National Security Interests in Personal Property Registry } \\ \text { PSOJ } & \text { Private Sector Organization of Jamaica } \\ \text { RADA } & \text { Rural Agricultural Development Authority } \\ \text { SIPPA } & \text { Security Interests in Personal Property Act }\end{array}$

All dollar amounts are U.S. dollars unless otherwise indicated. 


\section{TABLE OF CONTENTS}

Chapter 01 - Introduction 11

$\begin{array}{ll}1.1 \text { Background } & 11\end{array}$

1.2 Objective of the Assessment $r$

$\begin{array}{lr}1.3 \text { Approach } & 14\end{array}$

1.3.1 Phase One $r$

$\begin{array}{lr}\text { 1.3.2 Phase Two } & 14\end{array}$

$\begin{array}{lr}\text { 1.3.3 Phase Three } & 14\end{array}$

1.3.4 Phase Four 14

Chapter 02 - Understanding Asset-Based Lending and Common Secondary-Market Solutions 17

2.1 Overview $r$

2.2 A Holistic Framework for MABL $r$

$\begin{array}{lr}2.3 \text { A Focus on Secondary Markets } & 20\end{array}$

2.4 Key Lessons for Establishing Robust Marketplaces $\quad 20$

Chapter 03 - Movable Asset-Based Lending in Jamaica 23

$\begin{array}{lr}3.1 \text { Overview } & 23\end{array}$

3.2 Recent Developments: Issues and Challenges $r$

$\begin{array}{lr}3.3 \text { Conclusion } & 27\end{array}$

Chapter 04 - Summary of Results $\quad 29$

4.1 A Deep Dive into Movable Asset-Based Lending and Borrowing in Jamaica: Summary 29

Results of a Survey of Borrowers and Lenders $r$

4.2 Assets Frequently Purchased Secondhand $\quad 31$

4.3 Sourcing and Disposal of Movable Assets $\quad 31$

4.4 Disposal of Assets by Borrowers $\quad 33$

4.5 Responses from Lenders' Survey $\quad 33$

4.6 Summary from Inward Mission $\quad 38$

4.6.1 Market Informality and Fragmentation 38

4.6.2 Uncertainty and the Emphasis on Determining Anticipated Success 39

4.7 The Possible Impacts of COVID-19 Pandemic on MABL in Jamaica 40

4.7.1 Scope and Trends of the Coronavirus Pandemic 40

Chapter 05 - Summary Analysis of Key Secondary Markets in Jamaica 43

5.1 Case Study: Agri-Linkages Exchange (ALEX) Platform $\quad 45$

5.1.1 The Platform $r$

5.1.2 How the System Works $\quad 45$

$\begin{array}{lr}5.1 .3 \text { Challenges } & 45 \\ 5.1 .4 \text { Opportunties } & 47\end{array}$

$\begin{array}{lr}5.1 .4 \text { Opportunities } & 47\end{array}$ 
Chapter 06 - Final Recommendations 49

6.1 Key Features of the Portal 49

6.1.1 Registration of Buyers and Sellers 50

6.1.2 Inspection, Listing, and Valuation of Assets 50

6.1.3 Developing a Transparent Real-Time Auction System 50

6.1.4 Support for Online Payments 50

6.1.5 Maintaining a History of Transactions 50

6.1.6 Integration to Other Relevant Networks 50

$\mathbf{6 . 2}$ Value Added Services $\quad \mathbf{5 0}$

6.2.1 Delivery of Products 50

6.2.2 Feedback and Rating of Buyers and Sellers 50

6.2.3 Supporting Mechanisms and the Enabling Environment 50

6.2.4 Additional Issues 51

6.2.5 Possible Service Providers to Support the Development of the Portal 51

6.2.6 Ways That the Portal Addresses Key Requirements for Successful Secondary Markets

Chapter 07 - Conclusion 55

Appendix

Appendix A: Detailed Stakeholder Mapping 57

End Notes $\quad 59$

References 60 


\section{LIST OF FIGURES}

Figure 1: Methodology $\quad 14$

Figure 2: Access to Credit the Most Significant Barrier for Business $r$

Figure 3: Collateral as a Major Constraint to Accessing Financing among Business 18

Figure 4: Cash Cycles for MABL $\quad 18$

Figure 5: Framework for MABL $\quad 19$

Figure 6: Number of Registered Collateral Assets, 2015 to 2019

Figure 7: Percentage Classification of Movable Assets Utilized as Collateral in NSIPP 25

Figure 8: Registered Collateral by Sectors (Average, 2015 to 2019) 26

Figure 9: Registered Collateral by Debtor Type (Average, 2015 to 2019) 26

Figure 10: Value of Registered Collateral Assets (Average, 2015 to 2019) 27

Figure 11: Profile of Survey Respondents $\quad 29$

Figure 12: Source of Financing $\quad 30$

Figure 13: Key Assets Held by Manufacturers $\quad 30$

Figure 14: Purchase of Secondhand Assets by Borrowers 31

Figure 15: Sourcing of Machinery 231

Figure 16: Sourcing of Motor Vehicles $\quad 32$

Figure 17: Sourcing of Office Equipment $\quad 32$

Figure 18: Disposal of Assets by Borrowers 33

Figure 19: Survey of Lenders $\quad 33$

Figure 20: Rating of Collateral Assets $\quad 34$

Figure 21: Valuing Movable Assets $\quad 35$

Figure 22: Market Dynamics of Movable Assets $\quad 35$

Figure 23: Channels Used Most Frequently to Dispose of Movable Assets by Lenders 36

Figure 24: Frequent Buyers of Movable Assets $\quad 37$ 


\section{LIST OF TABLES}

Table 1: Types of Movable Assets Used by Key Registries

Table 2: Ranking of Movable Assets

Table 3: Valuation Mechanism Based on Movable Asset

Table 4: Frequent Buyers of Movable Assets 


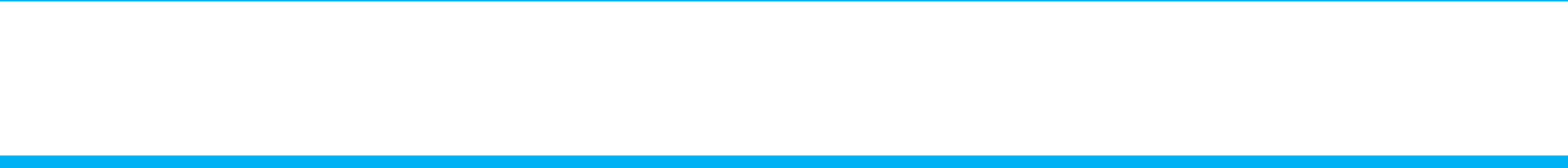

\section{CHAPTER 01}




\section{CHAPTER 01}

\section{Introduction}

\subsection{Background}

One of the critical challenges to micro, small, and medium enterprises (MSMEs) continues to be access to finance (World Bank 2019). Asset-based lending (ABL) is emerging as a unique financing option for businesses and a new way to provide working-capital financing to support business growth and sustain business operations. The approach leverages nontraditional but valuable movable assets such as machinery, equipment, securities, accounts receivable, agricultural produce, and intellectual property rights as collateral to secure financing from credit institutions. These assets are common among entrepreneurs and established businesses but are seldom considered as a useful form of collateral to access short-term financing. Interestingly, among developing countries, movable assets represent as much as 78 percent of the capital stock of enterprises relative to immovable assets such as land and buildings ( 22 percent) (Alvarez de la Campa 2011). Despite this, insufficient collateral continues to be one of the main reasons loans are not granted in emerging markets (Fleisig, Safavian, and de la Pena 2006), perhaps reflecting the preference of financial institutions to utilize collateral based on immovable assets such as land and buildings.

Lending based on movable assets is much more common in developed markets. In the case of the United States, more than 63 percent of loans to MSMEs are collateralized using movable assets (Calomiris et al. 2017). Through the work of the World Bank Group and the International Finance Corporation in particular, the use of lending based on movable assets continues to expand throughout the globe. Many best-practice examples can now be found in emerging markets such as Mexico, Colombia, Peru, Vietnam, and China, all of which have succeeded in expanding the use and application of movable asset-based lending (MABL) solutions. Indeed, increasing use of lending based on movable assets has resulted not only in an increase in financing available to MSMEs but also in the decline of credit costs and an increase in productivity levels among implementing countries (Alvarez de la Campa 2011).

For MABL to work effectively, a holistic framework is required. This includes a strong legislative and regulatory framework and the existence of key support institutions, such as credit bureaus and collateral registries. Information technology is also becoming integral to MABL to facilitate payments and also to connect with key stakeholders. For instance, online platforms such as Velotrade connect companies interested in trading in invoices to investors. It facilitates payments but also provides credit-analysis services. Innovative and diverse lending solutions are also being combined with robust information and communications technology infrastructure to facilitate payments, access information, and connect borrowers, lenders, investors, and regulators. All key stakeholders, such as legislators, regulators, valuators, credit analysts, software developers, brokers, lenders, borrowers, and lobbyists, have to work collectively to increase their understanding and use of MABL solutions.

A final key element of MABL is the presence of an active and liquid secondary market, particularly for the types of movable assets included in the registry. A functioning and liquid secondary market is crucial not only to facilitate the timely disposal of the assets but also to help creditors assess future values and, by extension, the level and terms of credit that should be extended. Secondary markets also give an idea of the possible risks in redeploying assets. They can also help financial institutions by assessing their risk exposure so that they can ensure that sufficient capital and regulatory provisioning requirements are met (Alvarez de la Campa et al. 2010).

Technology is also increasingly being leveraged to facilitate the growth and development of secondary markets. Online electronic-auction platforms are replacing physical auction marketplaces. These platforms are also able to link buyers and sellers both locally and internationally. Technology can also be used to connect a network of buyers, sellers, financiers, and the government. Online platforms are also able to increase the speed and lower the cost of transactions and to ease the collection and disbursement of cash.

In the case of Jamaica, in 2013 the Government of Jamaica, 


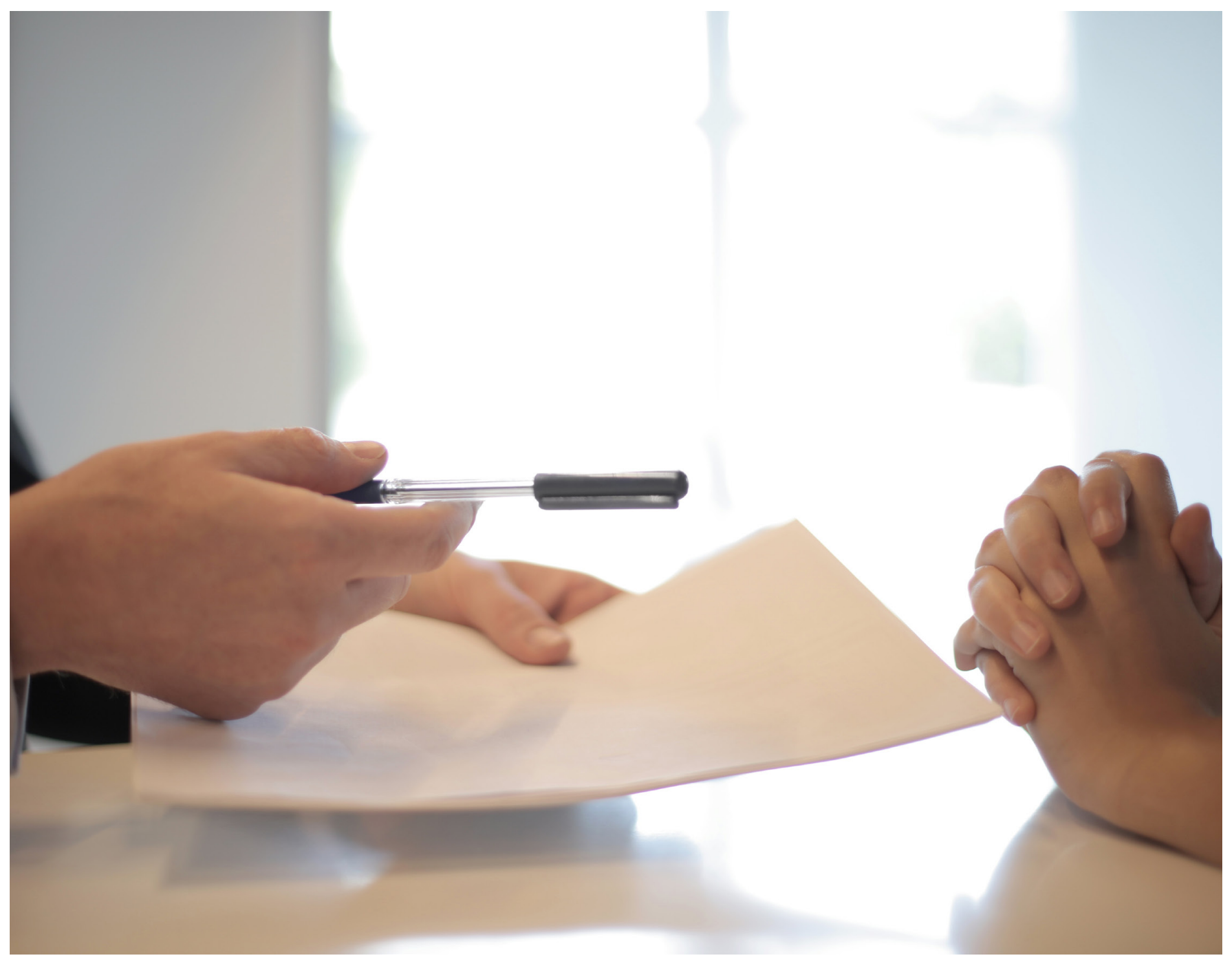

in an effort to increase the use of MABL, passed the Security Interests in Personal Property Act (SIPPA) and established the National Security Interests in Personal Property Registry (NSIPPR). The registry allows for the listing of collateral assets used for financing and so creates a priority of interest among creditors. It also helps track transactions between creditors and debtors. The SIPPA allows MSMEs and other businesses to offer movable assets and investments such as motor vehicles, agricultural products, livestock, securities, machinery and equipment, crops, patents, trademarks, and other forms of intellectual property as collateral for securing loans. As of 2018, the number of registrations within the registry had increased to just over 25,000 . The top three types of collateral used for financing include motor vehicles, furniture, and securities. Commercial banks are frequently cited to be conservative in their lending choices, and there is also a need to improve accounting processes and project evaluation and reporting among MSMEs. ${ }^{1}$ The government and its administrators have taken steps to increase the use of leasing, reverse factoring, and factoring as well as the functionality, confidentiality, and ease of transactions within the registry.
This assessment seeks to examine MABL in Jamaica, with a focus on developing possible options for deepening secondary markets among assets commonly used as collateral in MABL. The report includes recommendations for developing secondary markets, among other potential assets that can be used for MABL, as well as general steps for implementation. 
The NSIPPR has been in operation since 2014. While yearon-year use has increased, the registry is still considered underutilized. ${ }^{2}$ Such underutilization is an indicator that MABL is still failing to garner significant traction in the Jamaican economy. This study acknowledges this reality and advances one key argument: For MABL to work effectively, a holistic framework is required. In other words, the ability to register notices of security interests in movable property is merely one of the supporting mechanisms needed to deepen MABL. This assessment focuses on the establishment of secondary markets aimed at assessing and managing credit risk by minimizing uncertainty around asset valuation and liquidation. The assessment provides recommendations for the development of secondary markets in Jamaica. To achieve this, the following assessments were conducted:

- High-level analysis of the eligible movable assets that are relevant for credit institutions from the perspective of lending and provisioning

- High-level analysis of the primary and secondary markets for movable goods in Jamaica covering the following points:

- Whether categories of movable goods exist that are frequently sold in a populated network of buyers and are assessed by creditors for granting credit

- If a network exists, what types of individual items are transacted inside that network

- Whether prices hold consistent given similar type, quality, and quantity of goods, or there is price volatility - If prices are consistent, whether the network is reliable for setting secondhand values for the types of goods transacted therein.

- Whether the market created by these buyers is liquid and can absorb the regular volumes of goods placed for sale (to be shared by the client and key partners in Jamaica)

- Whether the goods are sold in a reasonably standard time frame or sales times vary

- If sale times vary, whether this is due to predictable seasonal patterns or any other reasons

- Whether there are industry, trade, or other associations that represent the network of sellers and buyers, and the nature of any incidence in sales in primary and secondary markets

- Whether technological or other tools exist to assist in the listing of goods for sale

- Whether technological or other tools are used to obtain the prices of goods for sale

- Whether a network of valuators can reliably predict the value of the goods sold in the future within this market, covering any specific valuation methodology used
- What tools are used in the market-online public auctions, online valuation tools, and so forth

- Challenges for the creation of such markets in the selected jurisdictions

- Recommendations for the development of secondary markets in Jamaica and any low-hanging opportunities (potential partners, including technological platforms) for project teams from the World Bank Group to consider 


\subsection{Approach}

\subsubsection{Phase One}

Phase 1 utilizes some information from the Inception Report, which provided a review of main studies on secondary markets for movable assets. The report outlined key pillars for the establishment of MABL globally. Additionally, we examine the leading secondary-market solutions that can be utilized for the main types of movable assets used in the Jamaican market with a specific focus on the manufacturing sector. Finally, we highlight issues, challenges, and trends related to MABL in Jamaica.

\subsubsection{Phase Two}

During Phase 2, results from this review were complemented with information gathered from focus groups. Focus-group meetings with lenders and borrowers were organized during our inward mission to Jamaica. A total of three focus groups were held: two with borrowers drawn from manufacturers and agro-processors operating in Jamaica and one with lenders (microlenders and commercial banks). Results from focus groups were complemented with information from indepth interviews with key industry stakeholders identified from the stakeholder map developed from the Inception Report. During this stage, the survey instrument was also pilot tested among focus-group participants and other industry stakeholders.

\subsubsection{Phase Three}

Triangulation of these results was achieved using data gathered from an online survey of lenders and borrowers (drawn from the agribusiness and manufacturers) operating in Jamaica. During this stage, the survey results were used to provide detailed information on the common movable assets utilized as collateral, as well as existing secondary markets used for the disposal of movable assets. Survey results are also likely to uncover emergent (and unforeseen) themes not found in the prior phases on the assessment.

\subsubsection{Phase Four}

During this phase, the survey results were analyzed and interview insights were gathered from Phases 2 and 3. This was done with a clear reference to best practices in setting up and operating secondary markets for movable assets in other jurisdictions (Phase 1). Insights that deviate from established best practices provided an opportunity to recommend strategies that can help develop a formal secondary market that fosters efficient trade.

Adequate consideration must be given to contextual heterogeneity within the Jamaican market. Recommendations must remain relevant and implementable in the Jamaican context (institutional factors, cultural and social norms, regulatory frameworks, technology access, and so forth).

Figure 1 outlines our approach for the final report.

Figure 1: Methodology

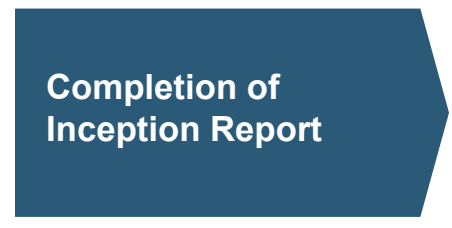

- Review of Secondary Reports

- Interviews with key stakeholders

- Design of questionnaire and survey methodology

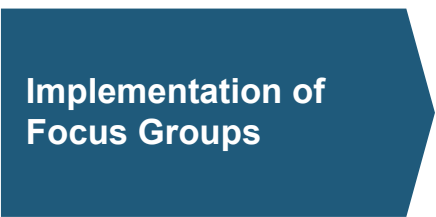

- Hosting of focus groups among lenders and borrowers drawn from the agribusiness and manufacturing sectors of Jamaica
Implementation of Survey to Lenders and Borrowers

- Execution of online survey to borrowers (microlenders and commercial banks) and borrowers (agro-business and manufacturing)
Analysis of Results and Finalization of Report

- Cleaning of data

- Analysis of results

- Drafting of final report 
This final report is outlined as follows: Chapter 2 provides a review of the literature on MABL and secondary markets. The case of MABL in Jamaica is outlined in Chapter 3, while Chapter 4 provides a deep-dive analysis of secondary markets in Jamaica based on a survey of borrowers and lenders. Chapter 5 provides a summary of secondary markets in Jamaica. Final recommendations for the establishment of a secondary-market solution are provided in Chapter 6, and conclusions are provided in Chapter 7. 


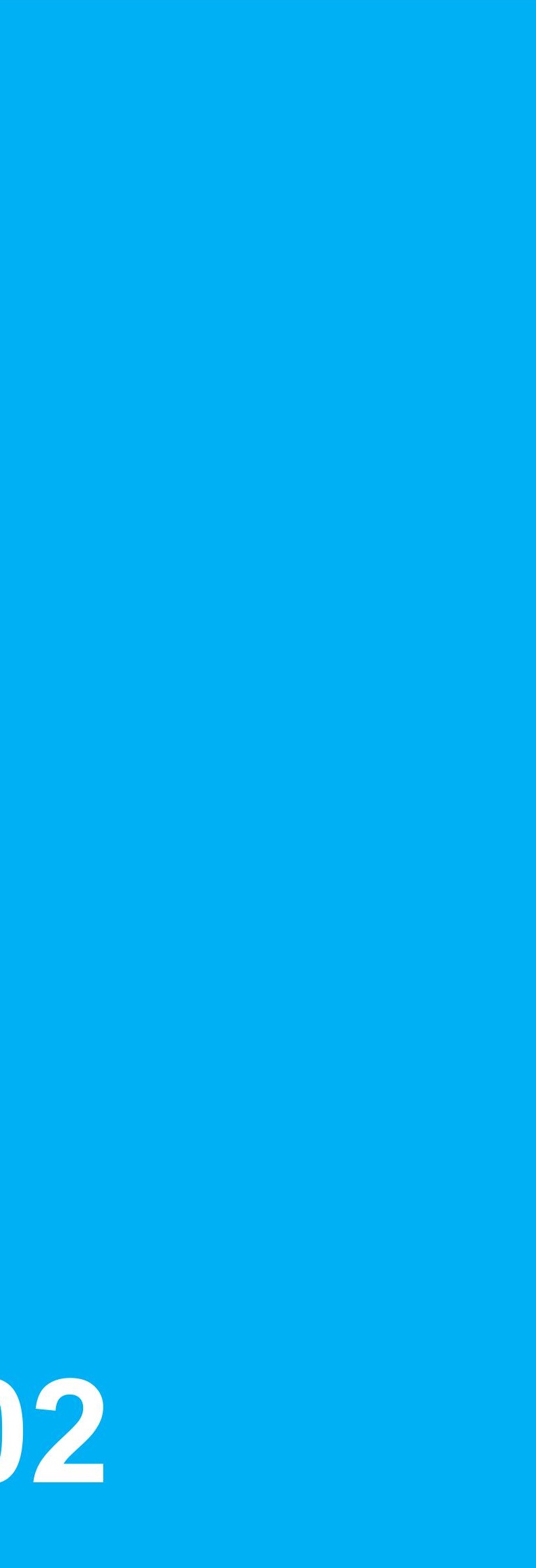




\section{Understanding Asset-Based Lending and Common Secondary-Market Solutions}

\subsection{Overview}

Finance has been a critical challenge to business development. The World Bank (2019), indicated that constrained access to credit remains among the most significant limitations to private-sector growth in many markets. Access to credit is crucial for economic growth and is the engine for privatesector development. In order to foster private enterprise productivity and promote formalization and the inclusion of the informal sector, several factor indicators need to be considered (Alvarez de la Campa 2011; Sultanov et al. 2019). These include developing modern credit infrastructure, removing barriers to a wide range of financial services, and enabling the development of innovative credit solutions The unavailability of assets is frequently not the problem; rather, it is the inability of the legal framework to facilitate the use of those assets as collateral. Financial institutions overwhelmingly prefer immovable assets as collateral. Preference toward immovable collateral is also reflected in the regulatory frameworks prescribing capital requirements for regulated financial institutions. In contrast, in the United States movable assets comprise about 60 percent of the enterprises' capital stock and account for around 70 percent of small-business lending (Sultanov et al. 2019). Based on the World Bank Enterprise Survey, access to finance remains a key challenge faced by businesses operating in the Latin American and Caribbean regions. (See figure 2.)
Specifically, access to collateral remains a main challenge for MSMEs wanting to secure credit for business operations. Paradoxically, the availability of assets is not often a problem for most MSMEs. This is because, in the developing world, movable assets often represent as much as 78 percent of the capital stock of an enterprise. In comparison, immovable assets such as land and buildings represent only 22 percent of total capital stock (IFC 2017). More often than not, credit applications may be declined on the grounds of insufficient collateral. Alternatively, borrowers may choose not to complete the application because they may perceive that they have inadequate collateral to back the value of the loan. (See figure 3.) What is frequently required is the legislative, institutional, and financial framework with accompanying secondary markets and enforcement mechanisms that can facilitate the deepening of ABL based on movable assets.

Figure 2: Access to Credit the Most Significant Barrier for Business

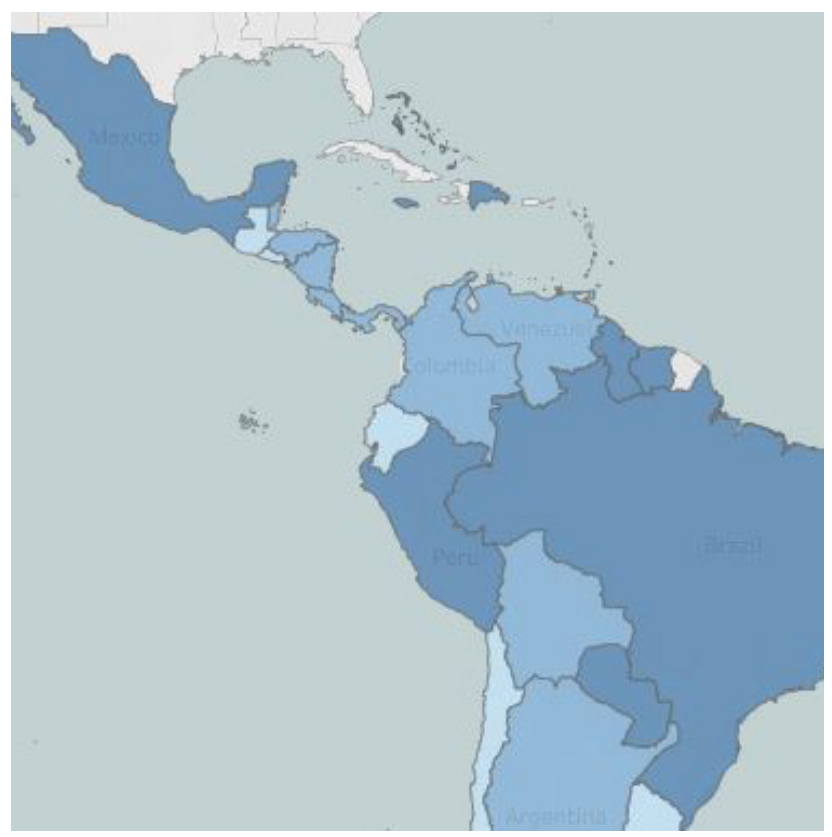




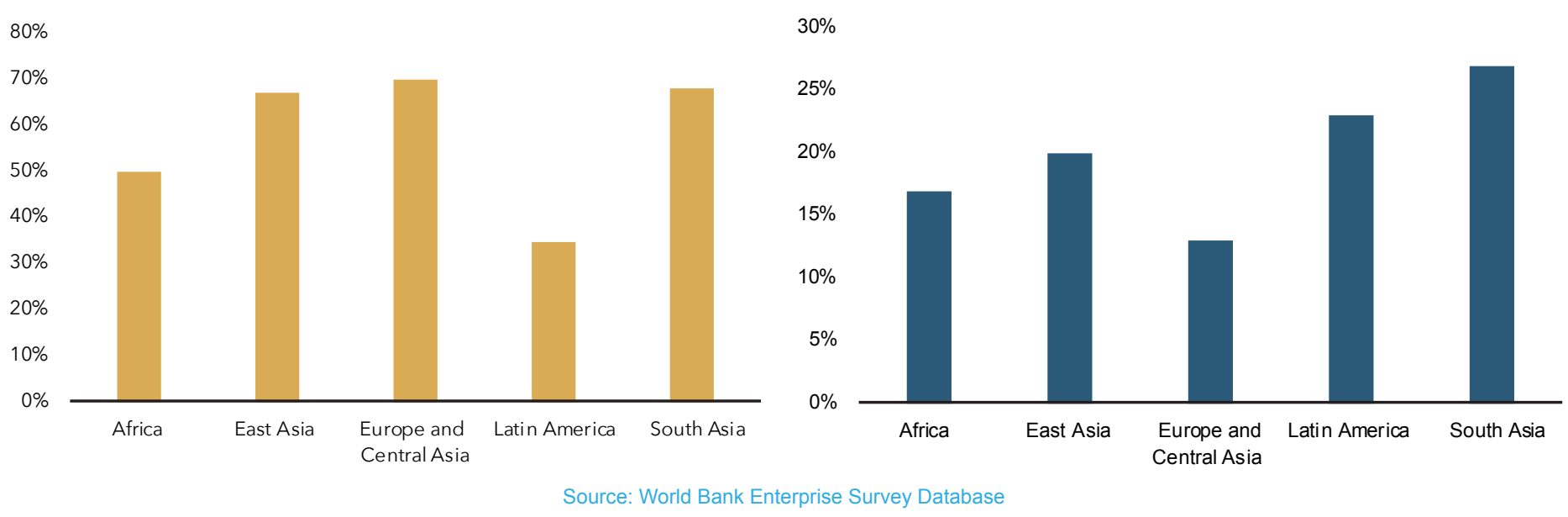

MABL is considered one of the most effective tools for

Figure 4: Cash Cycles for MABL providing credit to MSMEs since it provides financing throughout the enterprise's entire production or service cycle (Sultanov et al. 2019). As an example, a manufacturing company can access revolving MABL credit to facilitate working-capital financing using cash, securities, accounts receivable, or existing inventory as collateral (Sultanov et al. 2019). The company utilizes this credit to purchase raw materials and manufacture more products. Proceeds from the sale of these products are then deposited to a controlled account and used to repay the company's outstanding loan. (See figure 4.)

In instances where MABL and lending based on nontraditional assets have been introduced, there is an expansion in credit, a reduction in credit costs, and an increase in productivity (Alvarez de la Campa et al. 2010). Examples of the establishment of successful ABL regimes among emerging economies include Mexico, Vietnam, and Colombia. Examples in the more established markets include Canada (British Columbia and Nova Scotia) and New Zealand (Alvarez de la Campa, Downes, and Hennig 2011).

Assets frequently utilized for MABL can include the following:

- Motor vehicles

- Aircraft

- Equipment and machinery

- Securities - shares, bonds, and futures instruments

- Accounts receivable

- Agricultural produce, agro-processed products, and supplies

- Licenses, patents, and other forms of intellectual property 


\subsection{A Holistic Framework for MABL}

Figure 5 outlines a holistic framework that can be used to support MABL in host countries.

Figure 5: Framework for MABL

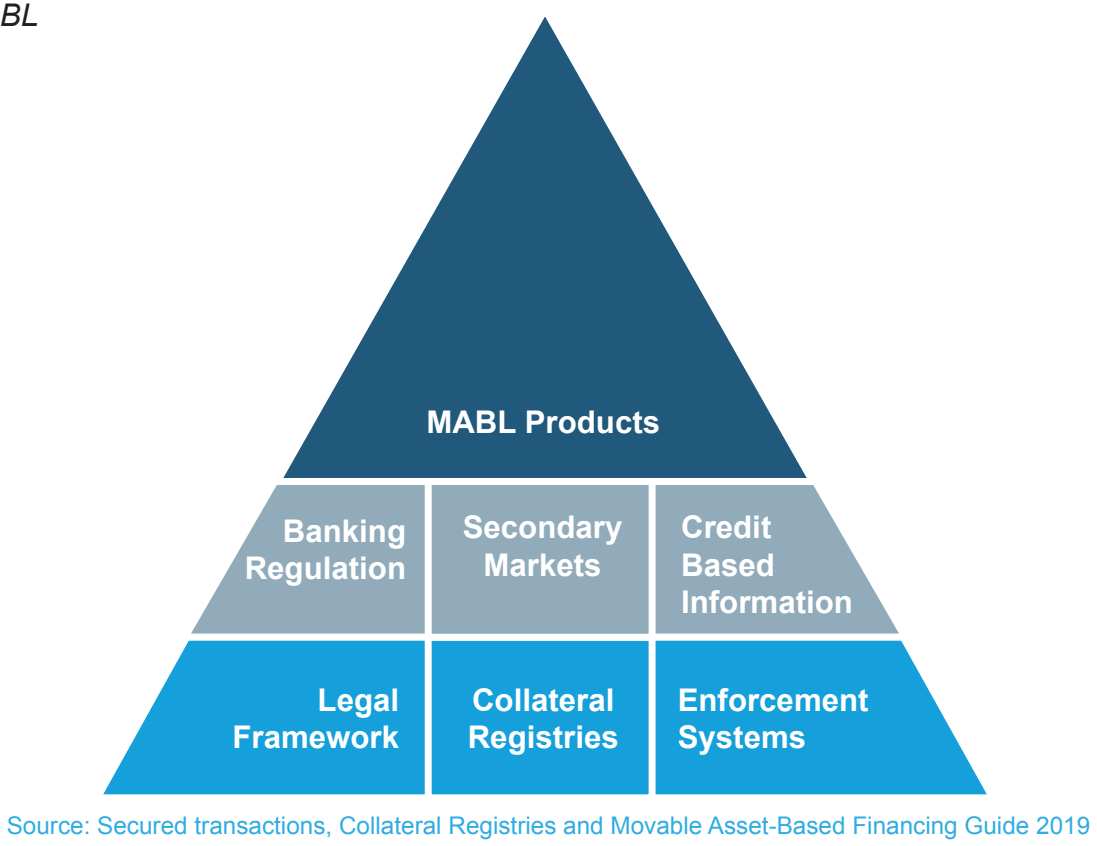

1. Legal framework: $A B L$ requires a secured transaction law that supports the use and recovery of all forms of present and future assets used by MSMEs for raising financing. Legislation should be based on the United Nations Commission on International Trade Law Model Law on secured transactions or other international standards and best practices.

2. Collateral registries: A modern collateral registry is also required. The registry requires registration for all forms of security interests in movables and functional equivalents, including leasing and factoring transactions. This registry provides a generic description of the collateral. In some instances, detailed information such as serial numbers or vehicle information numbers can be used to identify the associated asset. This information must be available for all third parties to search, so that it can be used to protect lenders from other third-party interests, which may have a lien on the assets of the borrower. The registrar's role is limited to verifying that data is inputted where required. Access to the registry should be available via online platforms.

3. Extrajudicial enforcement: Extrajudicial enforcement provides a much easier and faster recovery of assets (both tangible and intangible) by lenders in instances where borrowers may be in default. Usually, extrajudicial enforcement requires a forfeiture clause included in the security agreement, and a valuation of the asset can be included to ensure that a fair return can be obtained by the lender. An additional feature can be to include legal and technological frameworks to provide for online dispute resolution conducted by web-based systems.

4. Secondary markets: MABL assumes that an outstanding loan can be repaid by the asset used as collateral to secure credit financing. To this end, an active and liquid secondary market is required so that assets can be sold to repay loans. An active and well-structured secondary market is vital to support creditors' valuation of assets to be used as collateral and assessment of risk for more specialized types of assets. Associated with this is the presence of a network of valuators to establish accurate pricing of goods sold on the secondary market. Finally, it is also essential to assess the extent that online platforms exist that can facilitate listings and complete transactions of movable assets.

5. Banking regulations: Updated bank regulations are necessary to keep borrowing costs down and to facilitate the use of new movable assets as well as modern and updated financial solutions. As the regulatory environment for secured-transactions reforms improves, one can expect increased acceptance and usage of movable assets to mitigate credit risk in compliance with international financial regulations and standards.

6. Credit-based information: Credit bureaus are key for providing information on potential borrowers, as well as helping in the risk assessment of specific assets such as accounts receivables. 


\subsection{A Focus on Secondary Markets}

The terms "secondary market," "after-market," or "resalemarket" are used to refer to a system or place where a person or entity can transfer ownership of an asset. Secondary markets in MABL are typically used for the disposal of the assets. Disposal is frequently referred to as a resale transaction, rather than an originating transaction. However, information from secondary-market activity can also be used to assess the relative riskiness of potential assets to be used as collateral in future loans.

It is important to note that the development of secondary markets for movable assets depends very much on the type of secondary asset offered for resale, as well as the nature of the financing arrangement. For instance, disposal of equipment secured through a financial leasing arrangement may be completed quite easily through existing distribution channels within a lessor's network, among customers looking for cheaper lease options based on used equipment (CAK 2019). Alternatively, motor vehicles used as collateral for short-term loans may require a prior step to secure ownership, before it can be liquidated in established thirdparty car auctions.

Common examples of secondary markets include:

- Stocks, bonds, securities, and commodity marketspurchase ownership of shares that are resold to investors

- Car dealerships and auctions - purchase used cars that are sold to new owners

- Web-based online platforms-Amazon, eBay, Craigslist, "yard sale," and similar websites and platforms for consumers or investors to resell their goods

- Grocery stores and markets - sell agricultural products and supplies for resale to customers

- Consignment stores and thrift shops - provide a physical store for third-party products

\subsection{Key Lessons for Establishing Robust Marketplaces}

Generally, marketplaces are considered to be successful if profitable. More importantly, marketplaces are also places where buyers and sellers choose to transact to generate significant value through cost savings or to gain market share (Brunn, Jensen, and Skovgaard 2002). Stockdale and Standing (2003), in their examination of factors that are critical for successful online marketplaces, identify the following five key factors:

1. A critical mass of buyers and sellers: The number of buyers and sellers willing to transact on the marketplace needs to be sufficient. Strategies to achieve this include having relatively low entry and transaction costs to access value-added services.

2. Key income streams and sources: Income streams can come from transaction fees or commissions, membership or license fees, sale of industry information, valueadded services such as evaluation services, advertising, and marketing, and sale of accumulated marketing data (Gallaugher, Auger, and BarNir 2001).

3. Security: A secure environment to exchange commercially sensitive and financial information.

4. Trust and privacy: Trust in a marketplace can be signaled in the following ways:

a. Greater sharing among users and open feedback

b. The sharing of links to other websites

c. The presence of unbiased product information from third parties

d. The ability to develop a reputational or brand presence based on repeated interaction. Privacy stems from the need to protect sensitive information while maintaining industry relationships.

5. Technology and market infrastructure to facilitate market transactions: Slow and inefficient market infrastructure can raise transaction costs, increase operational risk, and hinder growth in the number of participants. Technology can be leveraged to lower costs, connect market participants, and facilitate payment and exchange. In some instances, there is the opportunity to link local markets to internationally accepted trading and settlement systems, which can lower start-up and learning costs for smaller emerging economies. Additionally, it is important to ensure that the legal and regulatory frameworks work in tandem to improve and deepen market infrastructure. ${ }^{4}$

6. Fulfilling participants' needs: To build upon and expand a network of users, it is important to identify and incorporate a relevant range of facilities to meet or exceed participants' needs. For instance, some community site facilities can also create trust and act as a one-stop portal for industry participants (Wise and Morrison 2000; Brunn, Jensen, and Skovgaard 2002). 
In the case of markets that focus on the sale for secondhand goods, Balocco, Perego, and Perotti (2010) highlight the following two additional essential features that ensure the success of such marketplaces:

7. Ensuring credibility and quality: The ability to guarantee the "credibility" of the sellers and to certify the quality of the products through different mechanisms

8. A targeted approach to buyers: The ability to reach a vast number of "targeted" buyers through advertising activities 


\section{Movable Asset-Based Lending in Jamaica}

\subsection{Overview}

The core legislative regime supporting Jamaica's effort to modernize and improve the availability of domestic credit in its private sector is centered on the National Security Interests in Personal Property Registry (NSIPPR), which is designed for the registration of security interests in movable assets that can be used as collateral to access credit, particularly for the MSME sectors. The registry is also hosted on a website where searches for notices of other security interests can be done by accessing the registry records. The Companies Office of Jamaica is the appointed registrar for the NSIPPR. All business and transactions are conducted online except for cases requiring direct payment.

The enabling legislation for the NSIPPR is the Security Interests in Personal Property Act (SIPPA) and corresponding regulations. The NSIPPA was passed in 2013 and is based on the following four fundamental principles: ${ }^{5}$

- Creation of security interests in any form of personal property (tangible or intangible, present or future)

- Clarification of priorities among the different claims, by creditors, on the secured property

- Public notification of security contracts

- Enforcement, by creditors, of property rights in the secured property, in an efficient manner

Key stakeholders involved in MABL in Jamaica can be grouped into three broad classifications as follows (see appendix A for detailed stakeholder analysis and mapping):

1. Regulatory and facilitative organizations: These institutions provide both oversight and facilitative functions for the various classes of movable assets and related financing mechanisms. This includes such key stakeholders as the Ministry of Industry, Commerce, Agriculture and Fisheries (MICAF), the key sponsor organization, and the Bank of Jamaica (BOJ). These institutions provide critical insights on the regulatory and oversight jurisdictions that govern the credit market generally. Other key organizations include the Development Bank of Jamaica (DBJ), which provides a range of financial, technical, and innovative solutions to support the growth and use of ABL in Jamaica within the existing legislative frameworks, and the Companies Office of Jamaica, where the NSIPPR is located and administered.

2. Financial institutions: Potential sources of financing for debtors (individuals and small and medium enterprises primarily in the manufacturing and related sectors.) These institutions would be the most likely sources for secured credit. They include commercial banks, development banks, and microfinancing organizations. They also include cooperative institutions such as credit unions, since, collectively, these institutions frequently work in tandem with banks and larger financing institutions, either as intermediaries or by providing pooling structure(s) that create economies of scale that are attractive to the banks. Engagement with this group is a high priority to determine their experiences to date with the NSIPPR and to solicit their specific needs and recommendations for (increased) utilization of MABL.

3. Borrowers and membership organizations: Consumers, farmers, MSMEs, and larger firms make up the bulk of potential borrowers who may utilize movable assets to secure credit and access finance. A very high percentage of potential debtors can also be found within umbrella organizations such as the Small Business Association of Jamaica/MSME Alliance, Private Sector Organization of Jamaica (PSOJ), Jamaica Chamber of Commerce, and the Jamaica Manufacturers and Exporters Association (JMEA). Prioritization of the above stakeholders within each class will depend on such factors as (1) membership levels, (2) the active participation of members, (3) a willingness to partner to conduct focus-group exercises, (4) the ability to champion survey responses from members, and (5) access to key personnel (liaisons). 


\section{lenges}

MABL has been on the rise in Jamaica, as indicated by the number of new collateral assets that have been registered on the NSIPPR, which now averages about 25,000 new registered collateralized assets. Loans to MSMEs now average 11 percent of total credit in 2016 (Senior 2012). Collectively, the MSME sector contributes almost 43 percent of Jamaica's gross domestic product (Torero et al. 2006).

The Government of Jamaica has done much to create the legislative, regulatory, and institutional environment to support MABL. Apart from the enactment of SIPPA and establishment of the NSIPPR, there is a robust commonlaw framework. BOJ recently introduced a principles-based approach to the assessment of collateral to prudential

Figure 6: Number of Registered Collateral Assets, 2015 to 2019 banking regulations, as well as modern accounting standards to facilitate increased use of movable assets as collateral in lending agreements. Institutions such as credit bureaus, ${ }^{6}$ MICAF, and DBJ support the expansion of MABL in Jamaica. More recently, DBJ completed studies on the use of factoring and leasing in Jamaica, ${ }^{7}$ while MICAF also recently completed an "Operational Review of the Secured Transaction Regime in Jamaica." Recommendations from these studies are currently being implemented to support the increased usage of these forms of MABL locally.

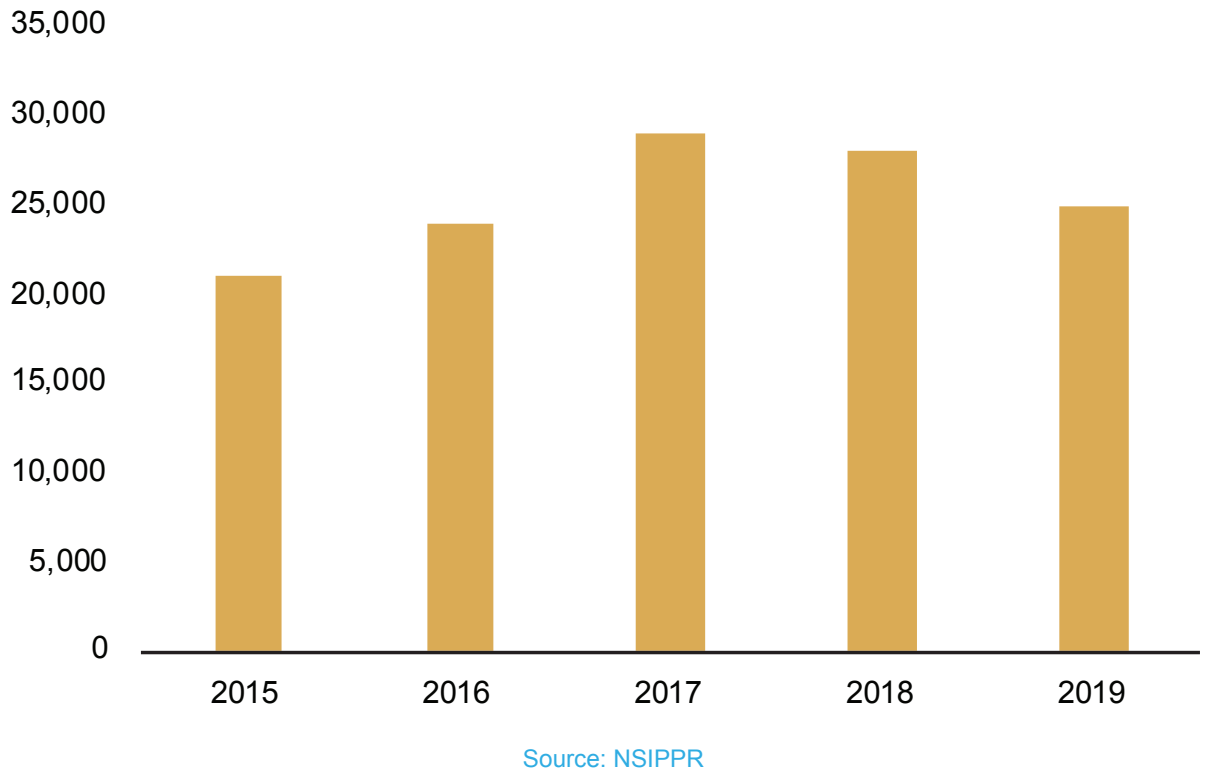

While some financial institutions and informal lenders do not yet utilize the registry, ${ }^{8}$ table 1 details the types of assets used in the Jamaican registry relative to other key registries located around the globe. Despite the diversity of assets listed in the registry, motor vehicles represent by far the largest percentage of registered assets ( 79 percent), followed

closely by furniture (10 percent) and other types of assets such as jewelry (figures 6 and 7). Based on focus-group discussions, it can be inferred that the preponderance of motor vehicles could be attributed to the fact that this asset can be valued and disposed of easily relative to other assets used in the registry. 


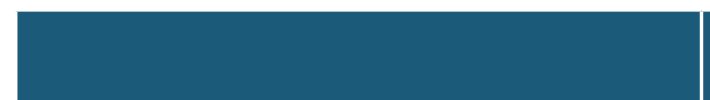

\section{Jamaica}

\begin{tabular}{c|c}
$\begin{array}{c}\text { Canada } \\
\text { (BC) }\end{array}$ & United \\
States (TX)
\end{tabular}

Bangalesh

New
Zealand

Mauritus

\section{Type of asset used as collateral}

Universal security over present and future

Machinery and Equipment

\section{Motor Vehicles}

Agricultural Products

Crops and other agricultural yields

Livestock

Investment Property

Documents of rights, financial instruments

Intellectual Property

A single account recievable

Multiple account recievable

Inventory

Memebership and partnership interests

Futures and Securities

\begin{tabular}{|c|c|c|c|c|c|}
\hline & & & & & \\
\hline$\checkmark$ & $\checkmark$ & $\checkmark$ & $\checkmark$ & $\checkmark$ & $\checkmark$ \\
\hline$\checkmark$ & $\checkmark$ & $\checkmark$ & $\checkmark$ & $\checkmark$ & $\checkmark$ \\
\hline$\checkmark$ & $\checkmark$ & $\times$ & $\checkmark$ & $\checkmark$ & $\checkmark$ \\
\hline$\checkmark$ & $\checkmark$ & $\checkmark$ & $\checkmark$ & $\checkmark$ & $\checkmark$ \\
\hline$\checkmark$ & $\checkmark$ & $\checkmark$ & $\checkmark$ & $\checkmark$ & $\checkmark$ \\
\hline$\checkmark$ & $\checkmark$ & $\checkmark$ & $\checkmark$ & $\checkmark$ & $\checkmark$ \\
\hline$\checkmark$ & $\checkmark$ & $\checkmark$ & $\checkmark$ & $\checkmark$ & $\checkmark$ \\
\hline$\checkmark$ & $\checkmark$ & $\checkmark$ & $\checkmark$ & $\checkmark$ & $\checkmark$ \\
\hline$\checkmark$ & $\checkmark$ & $\checkmark$ & $\checkmark$ & $\checkmark$ & $\checkmark$ \\
\hline$\checkmark$ & $\checkmark$ & $\checkmark$ & $\checkmark$ & $\checkmark$ & $\checkmark$ \\
\hline$\checkmark$ & $\checkmark$ & $\checkmark$ & $\checkmark$ & $\checkmark$ & $\checkmark$ \\
\hline$\checkmark$ & $\checkmark$ & $\checkmark$ & $\checkmark$ & $\checkmark$ & $\checkmark$ \\
\hline$\times$ & $\checkmark$ & $\checkmark$ & $\times$ & $\checkmark$ & $\checkmark$ \\
\hline$\checkmark$ & $\checkmark$ & $\checkmark$ & $\checkmark$ & $\checkmark$ & $\checkmark$ \\
\hline Source: Love, Pería, and Singh 2016 & & $\checkmark$ & \\
\hline
\end{tabular}

Figure 7: Percentage Classification of Movable Assets Utilized as Collateral in NSIPP
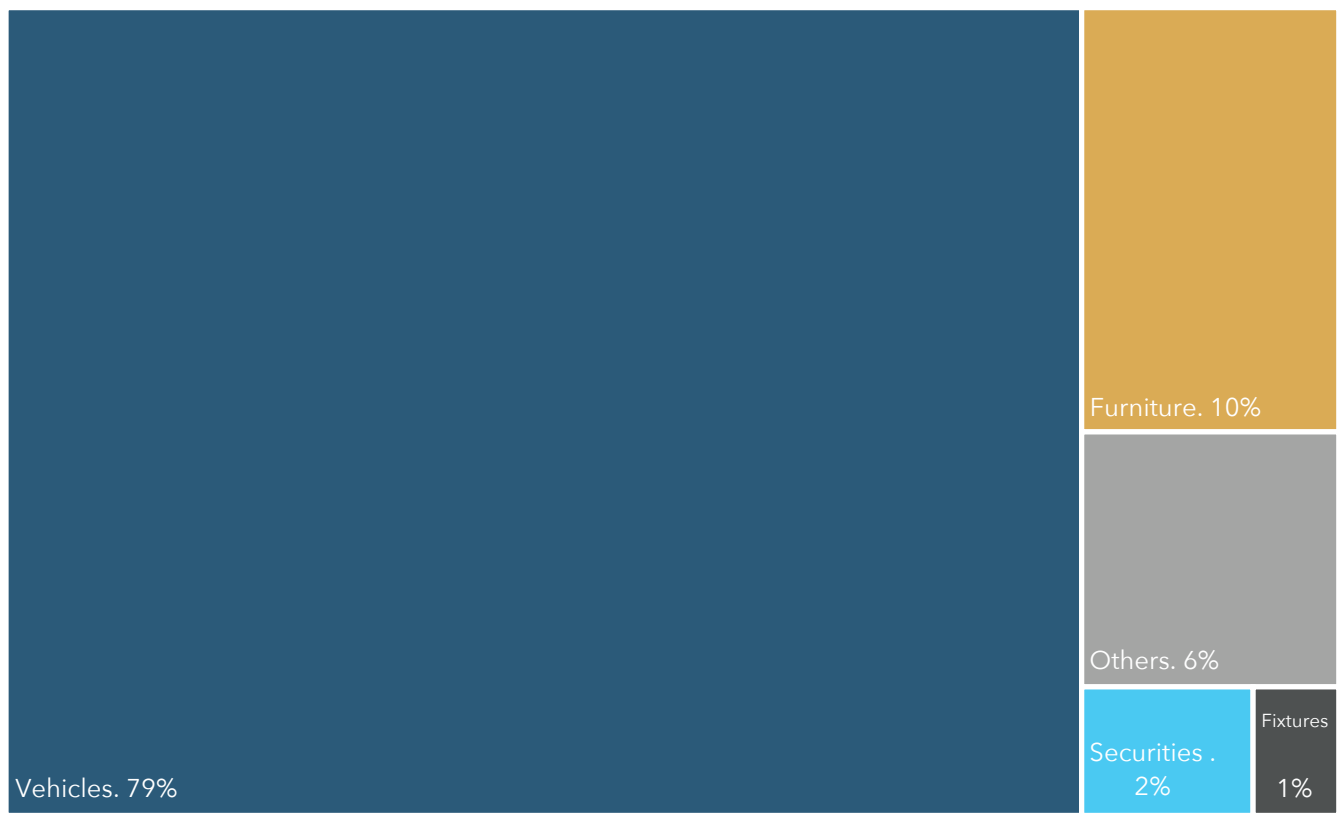

Source: NSIPPR

Currently, MABL is being offered by some key financial institutions such as commercial banks and key microlending organizations (Senior 2012). The main forms of MABL undertaken include reverse factoring, financing based on warehouse receipts, and operating leases. While credit is currently expanding, more can be done to expand the use of MABL.
Unfortunately, based on usage, consumers represent the majority of borrowers (over 63 percent) and over 83 percent of the collateral used to secure individual loans. Commercial customers represent just 5.7 percent of registry with MSMEs, representing over 8.8 percent of the borrowers. (See figures 8 and 9.) 
Figure 8: Registered Collateral by Sectors (Average, 2015 to 2019)

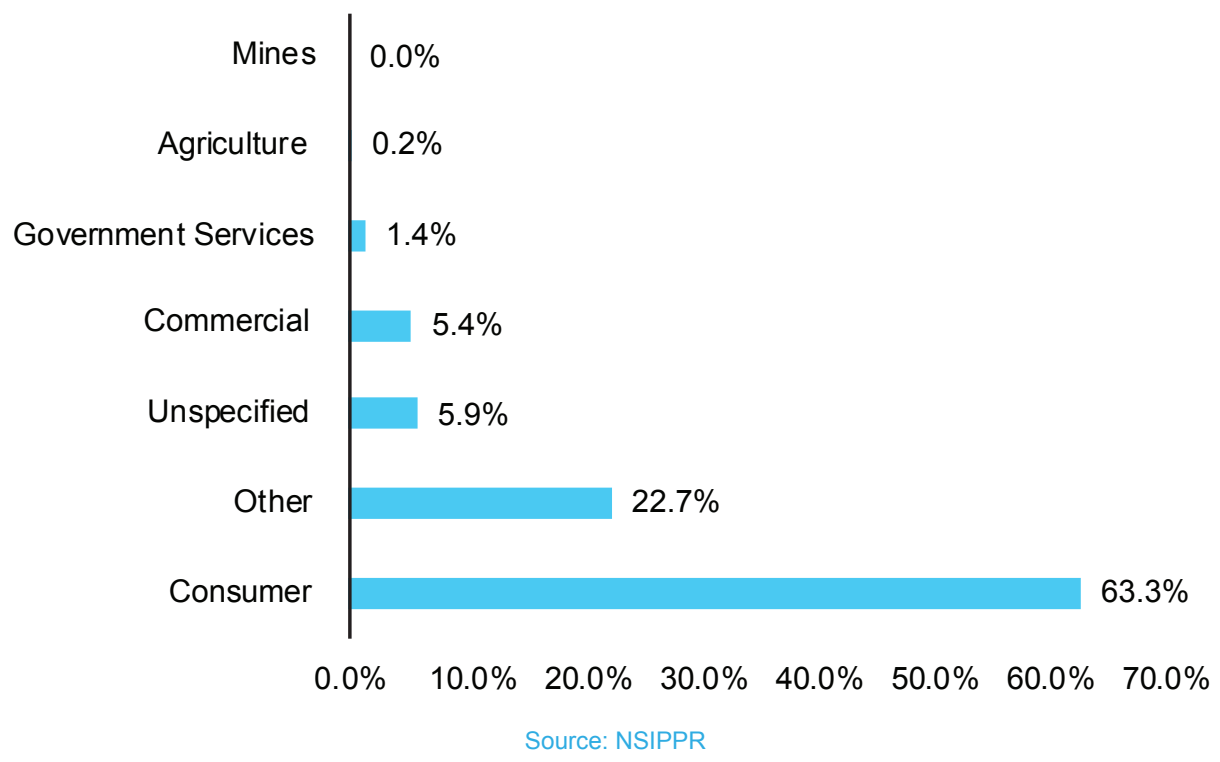

Figure 9: Registered Collateral by Debtor Type (Average, 2015 to 2019)

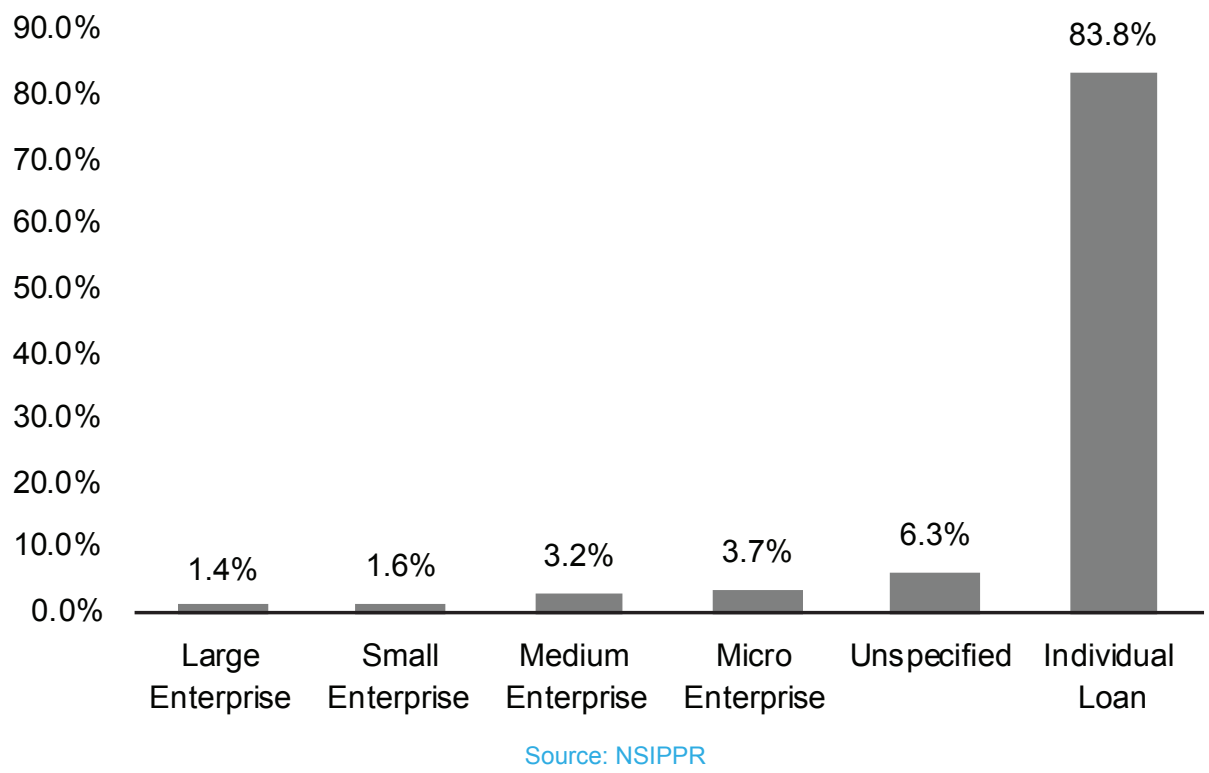

Finally, in terms of the average value of collateralized loans or assets, the latest estimates place the value between $\$ 5,325$ and \$53,250 (figure 10). 


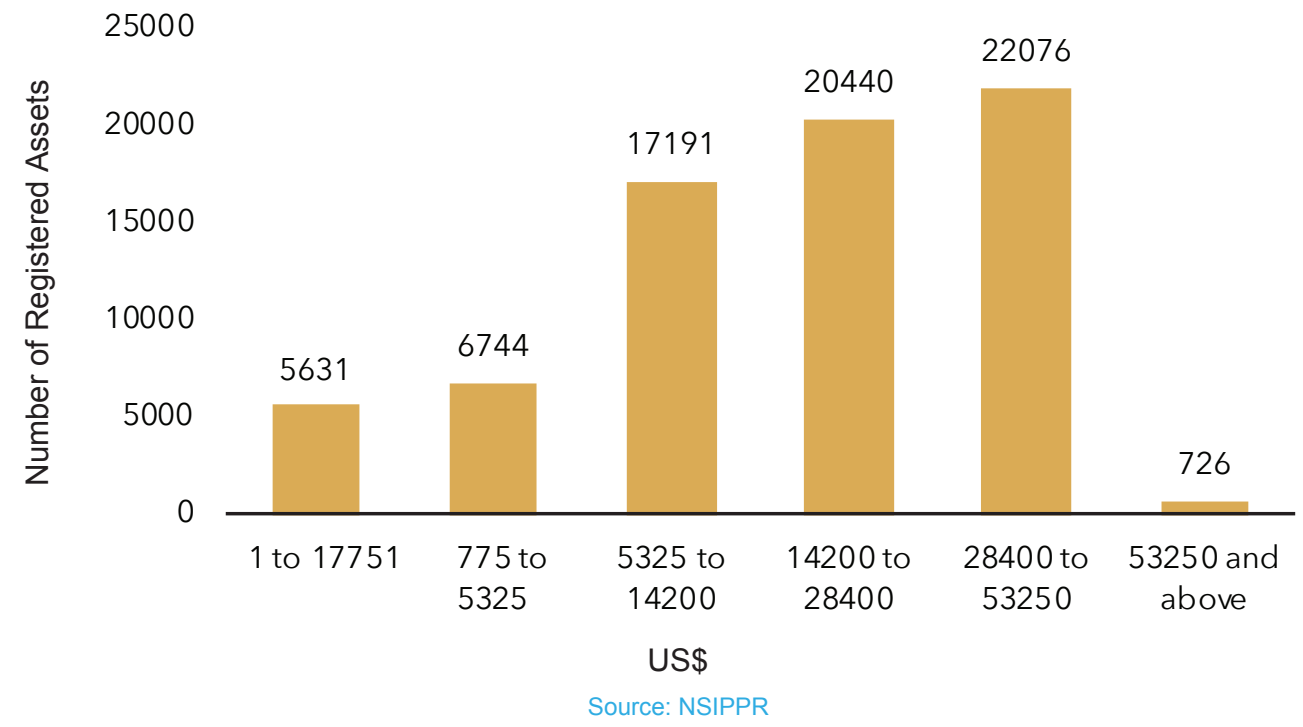

\subsection{Conclusion}

Based on this analysis, we continue to see an increase in the number of loans secured with collateral based on movable assets in Jamaica. The most common collateral asset registered on the registry is motor vehicles, and the most common clients are consumers and individuals as opposed to businesses and microenterprises.
To this end, despite the growth in lending, there is considerable scope for increasing the types of movable assets used as collateral to finance credit transactions, as well as increasing the types of clients that utilize this form of borrowing. 


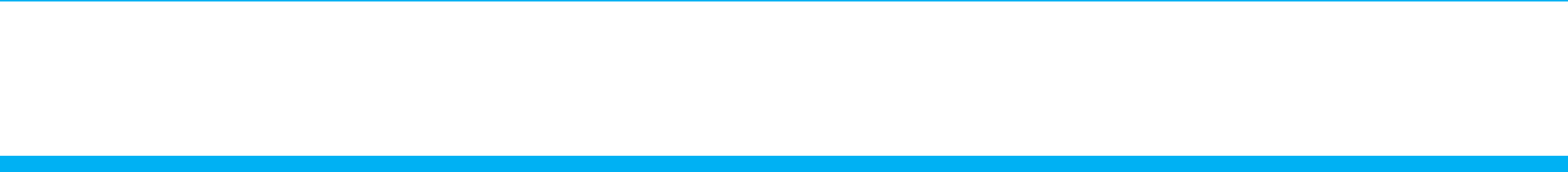

\section{CHAPTER 04}




\section{CHAPTER 04}

\section{Summary of Results}

\subsection{A Deep Dive into Movable Asset-Based Lending and Borrowing in Jamaica: Summary Results of a Survey of Borrowers and Lenders}

Of the 146 respondents, approximately 58 percent were manufacturers, while 24 percent were classified as agroprocessors. The remaining 18 percent were lending organizations. More than 59 percent of respondents reported being in operation for over 15 years, while only 16 percent of respondents reported being in operation for less than five years, reflecting the overall maturity of the sample in terms of operation. An even distribution was also evident in the size of businesses (measured by the number of employees). The data indicated that approximately 36 percent of respondents employed 50 or more employees. Microenterprises comprised 17 percent of the sample (employing fewer than five persons).

Figure 11: Profile of Survey Respondents

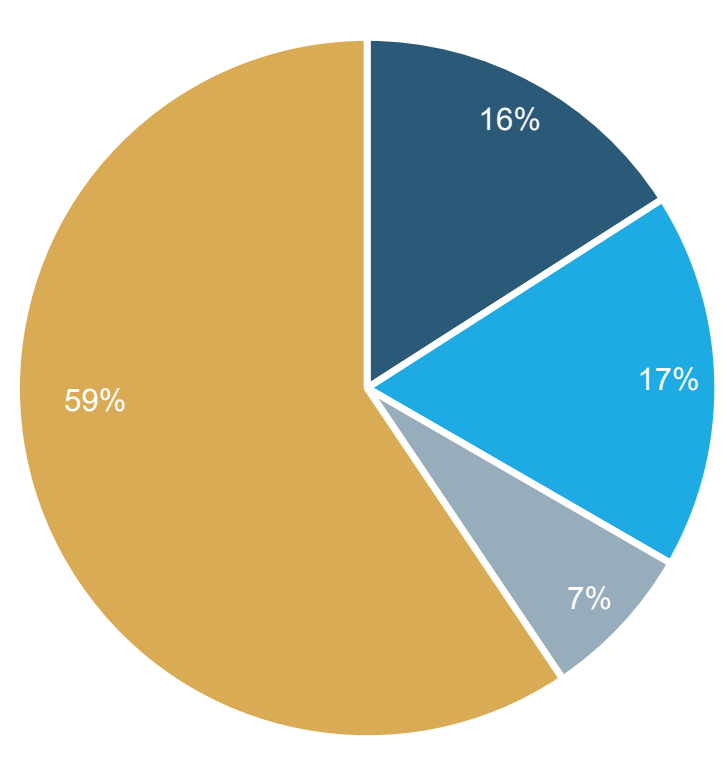

- Less than 5 years Between 5 and 10 years

- Between 10 and 15 years - More than 15 years

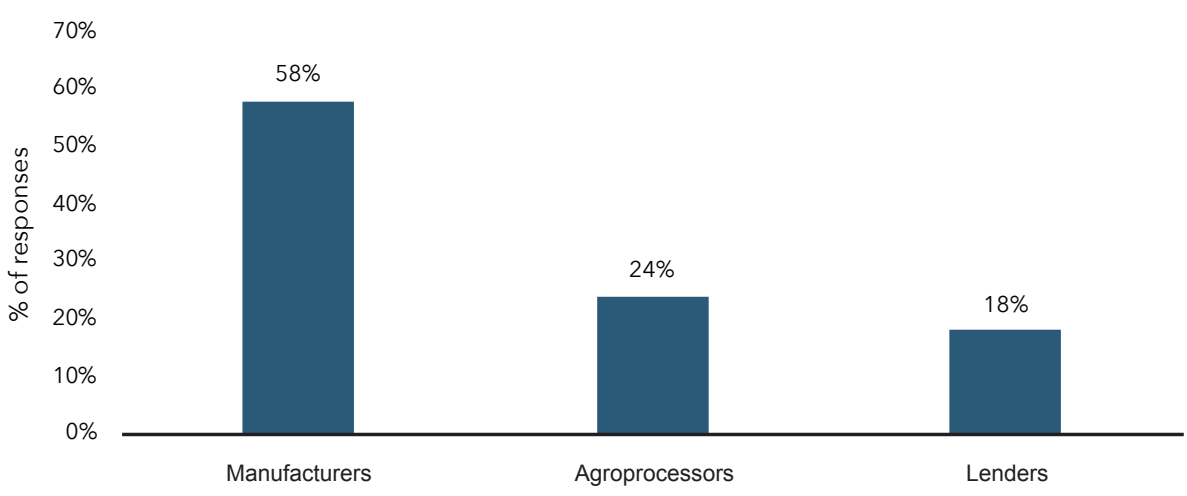


In terms of borrowers (manufacturers and agribusiness enterprises), approximately 27 percent of the sample sourced their financing from savings and loans and commercial banks. Other sources of funding included state-owned banks and the government (lending and grants), family and friends, cooperatives and credit unions, microlenders, and informal pawn shops. Interestingly, 13 percent of the sample did not secure any loans in the last year. (See figure 12.)

Figure 12: Source of Financing

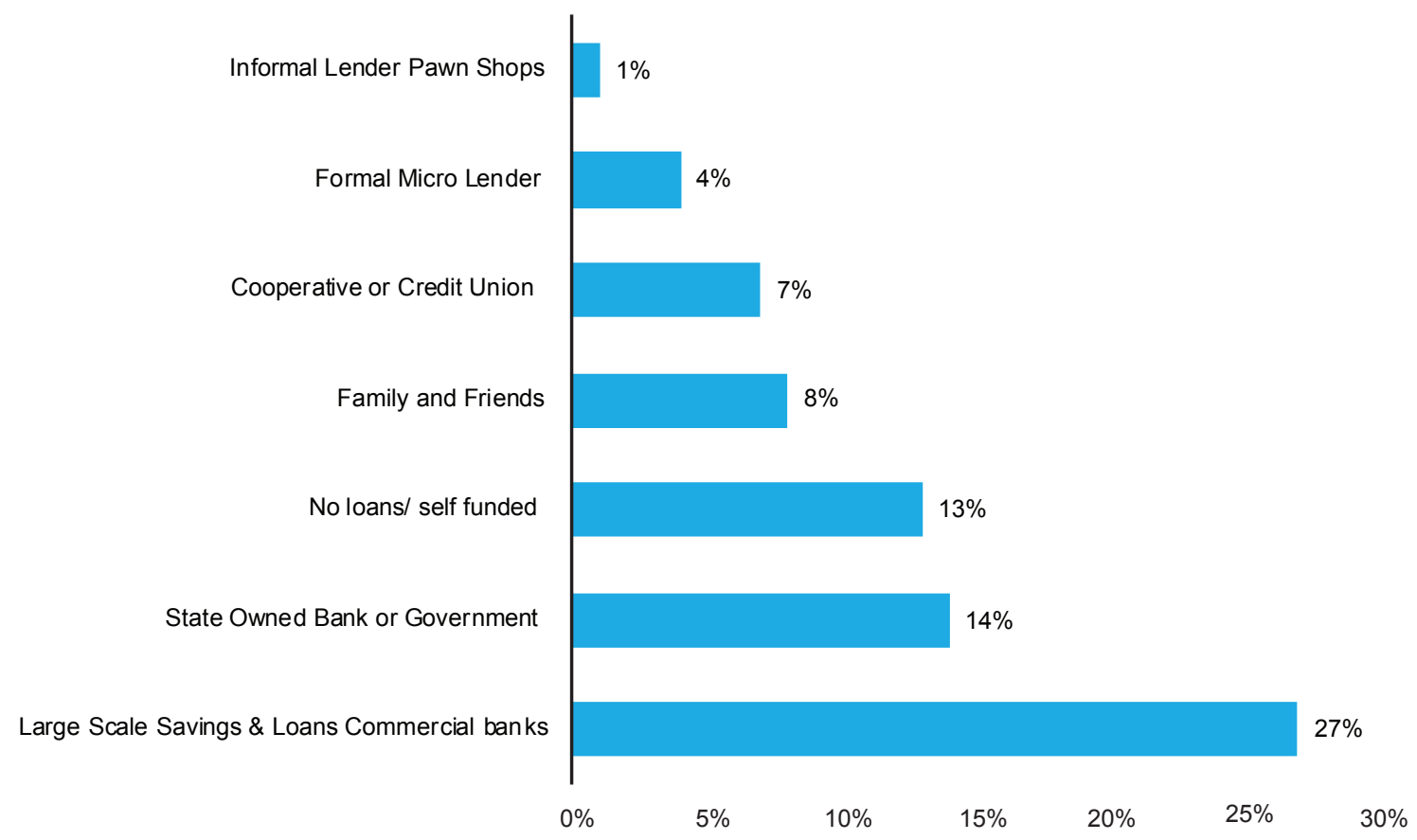

In terms of assets, machinery ( 60.8 percent), office equipment (58.8 percent), inventory (51 percent), accounts receivable (48.3), and motor vehicles (41.2 percent) were the assets listed most commonly by manufacturers. Interestingly, 33 percent of the respondents listed intellectual property rights (IPRs) as a form of asset held by the companies. Crops and securities were the assets least frequently held by these respondents.

Figure 13: Key Assets Held by Manufacturers

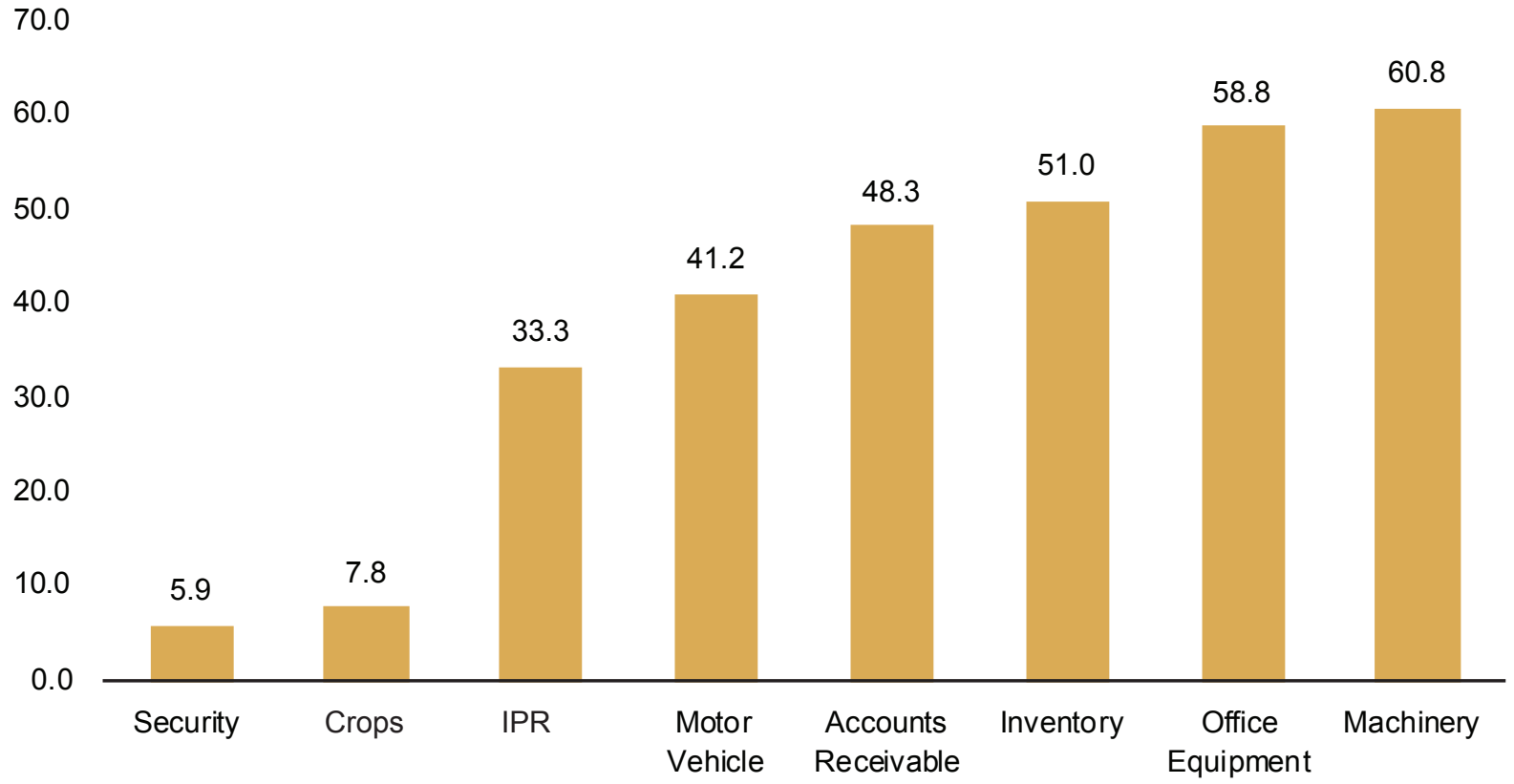


Figure 14: Purchase of Secondhand Assets by Borrowers

$60.0 \%$

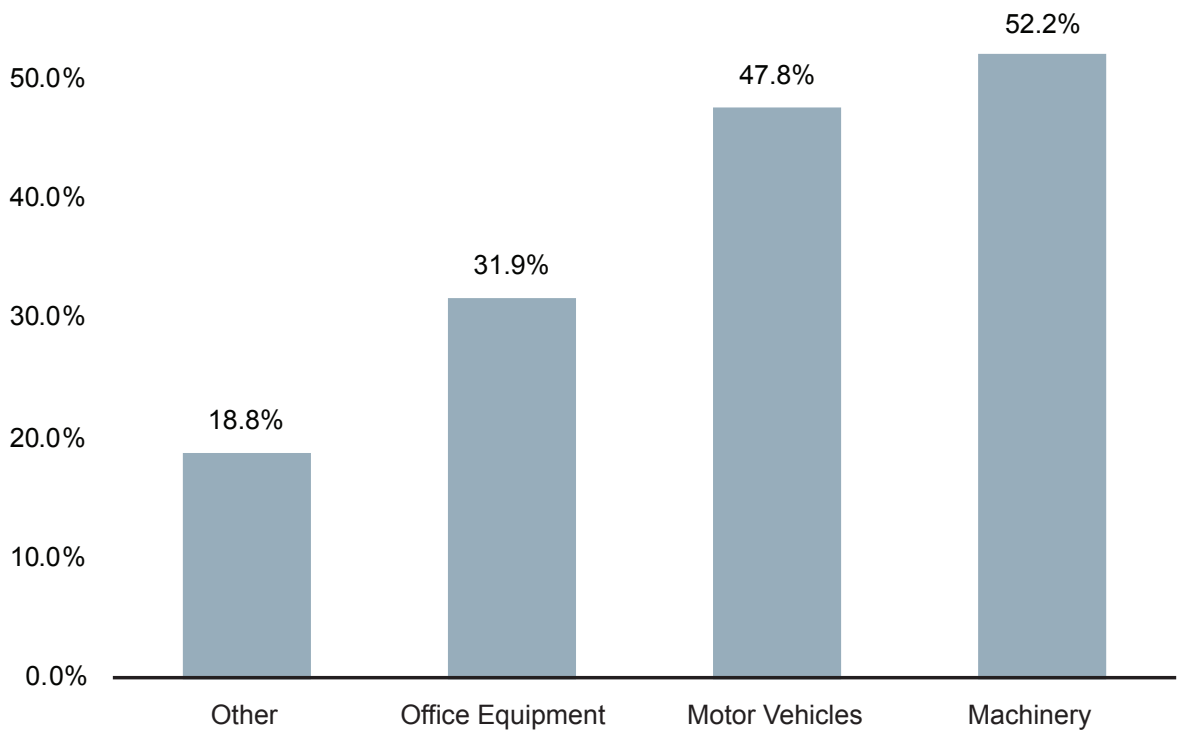

Interestingly, respondents also frequently purchased secondhand assets. Specifically, machinery, motor vehicles, and office equipment were the assets purchased most frequently by secondhand means (figure 14).

\subsection{Sourcing and Disposal of Movable Assets}

Respondents utilized such means as newspaper classified ads, dealerships, online portals, industry associations, and word of mouth to source secondary assets. However, channels varied based on assets required. Specifically, as seen in figure 15, online sources, newspaper classified ads, and international suppliers were the three most common channels used to source machinery. Car dealerships, newspaper classified ads, and word of mouth were the most common channels used to source motor vehicles (figure 16). Finally, newspaper classified ads, local dealers, and word of mouth were the top three channels used to source office equipment. (See figure 17.)

Figure 15: Sourcing of Machinery

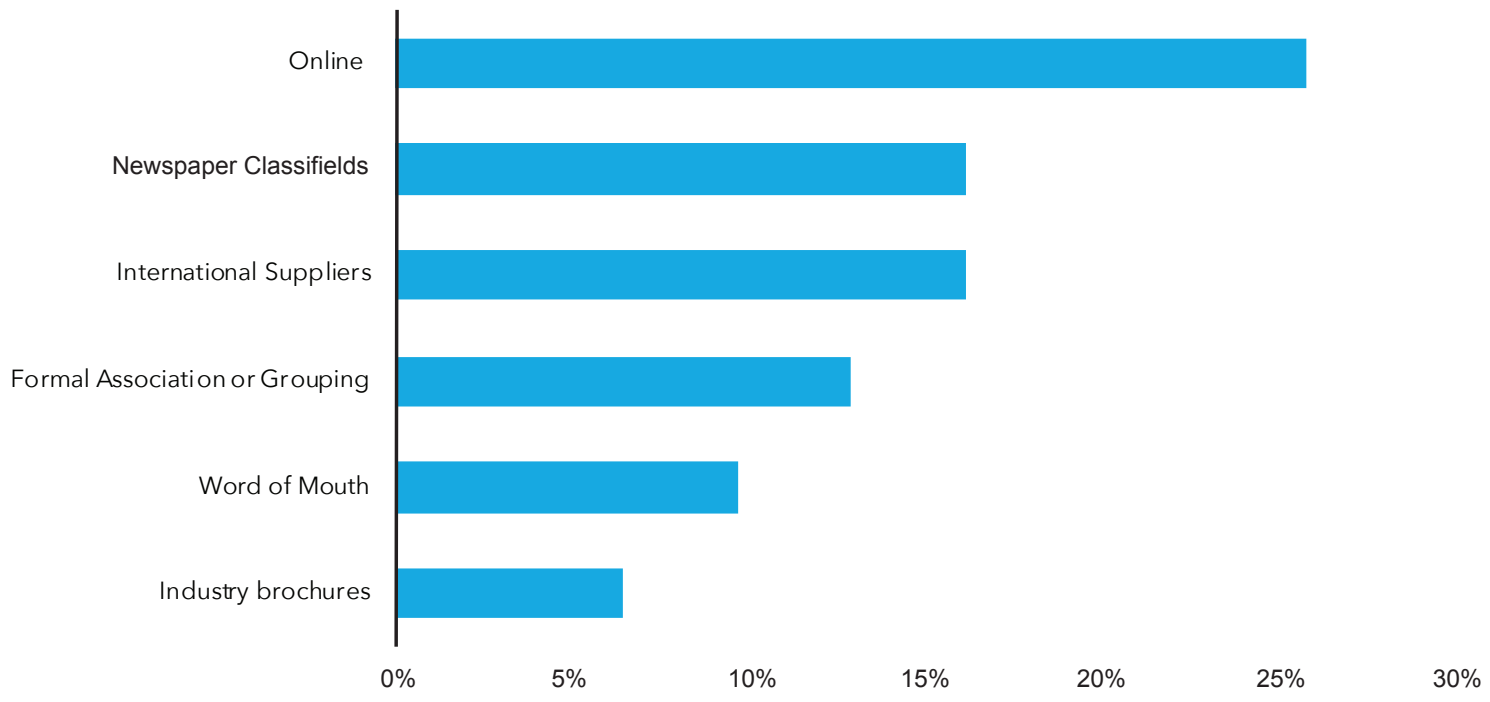




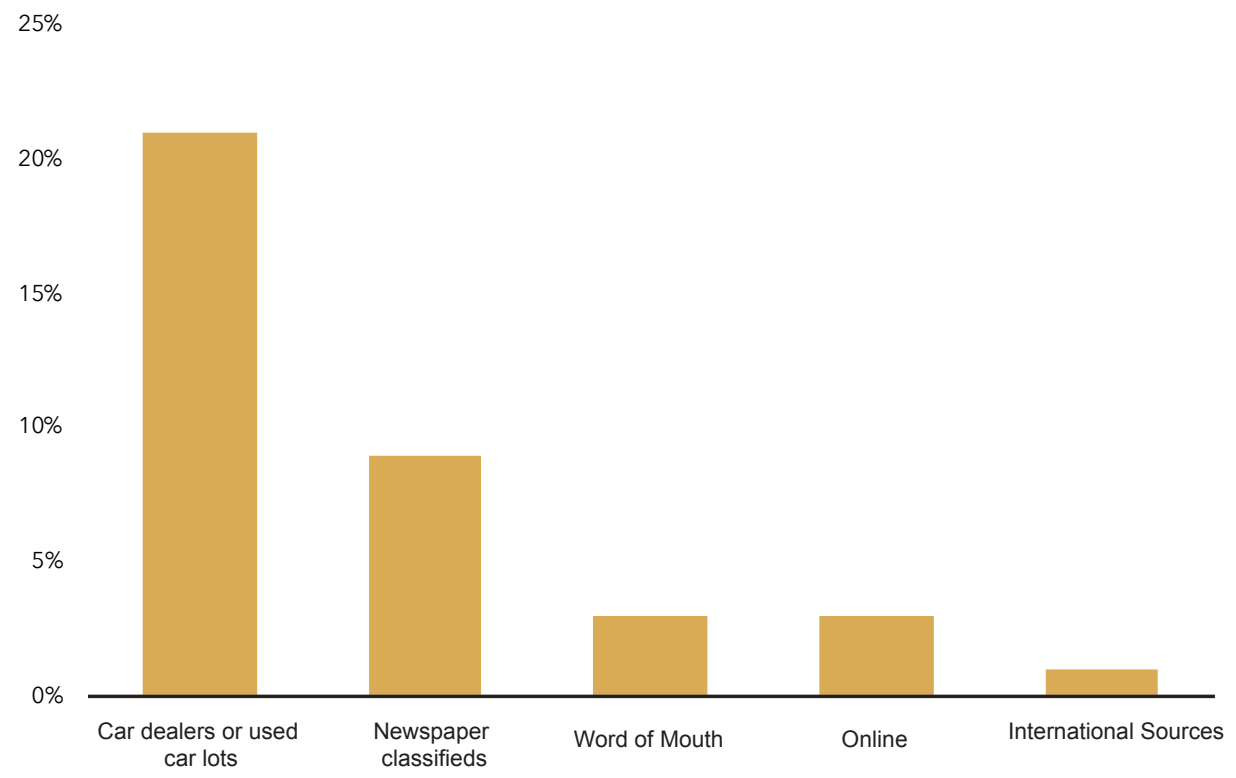

Figure 17: Sourcing of Office Equipment

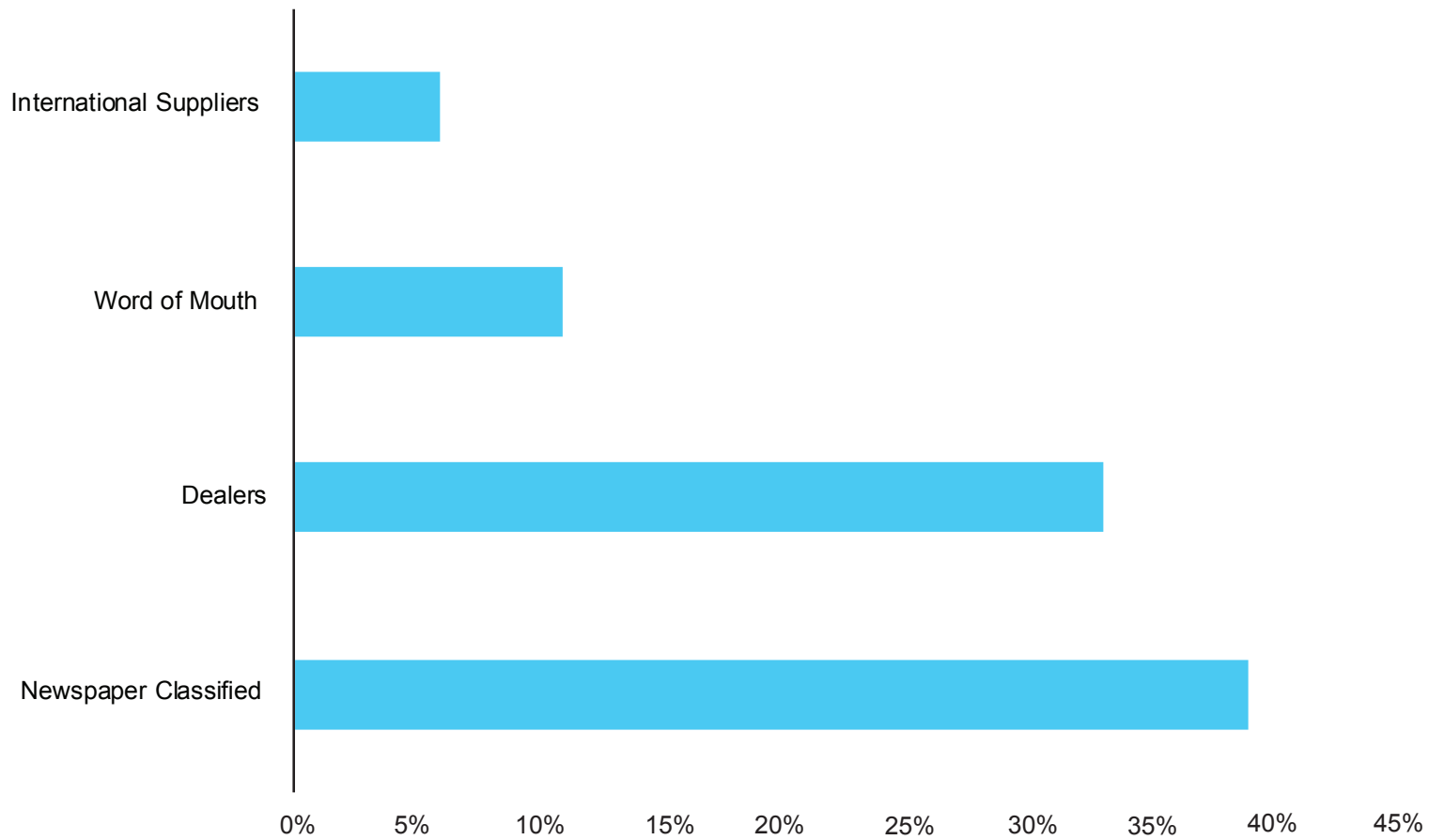


As seen in figure 18, newspaper classified ads remain the most popular means to dispose of assets (motor vehicles, machinery, and office equipment). However, a significant portion of the sample indicated that they chose not to dispose of their assets over time. In many instances, respondents indicated that they would keep assets for spare parts or, in other cases, to dump or recycle assets.

Figure 18: Disposal of Assets by Borrowers

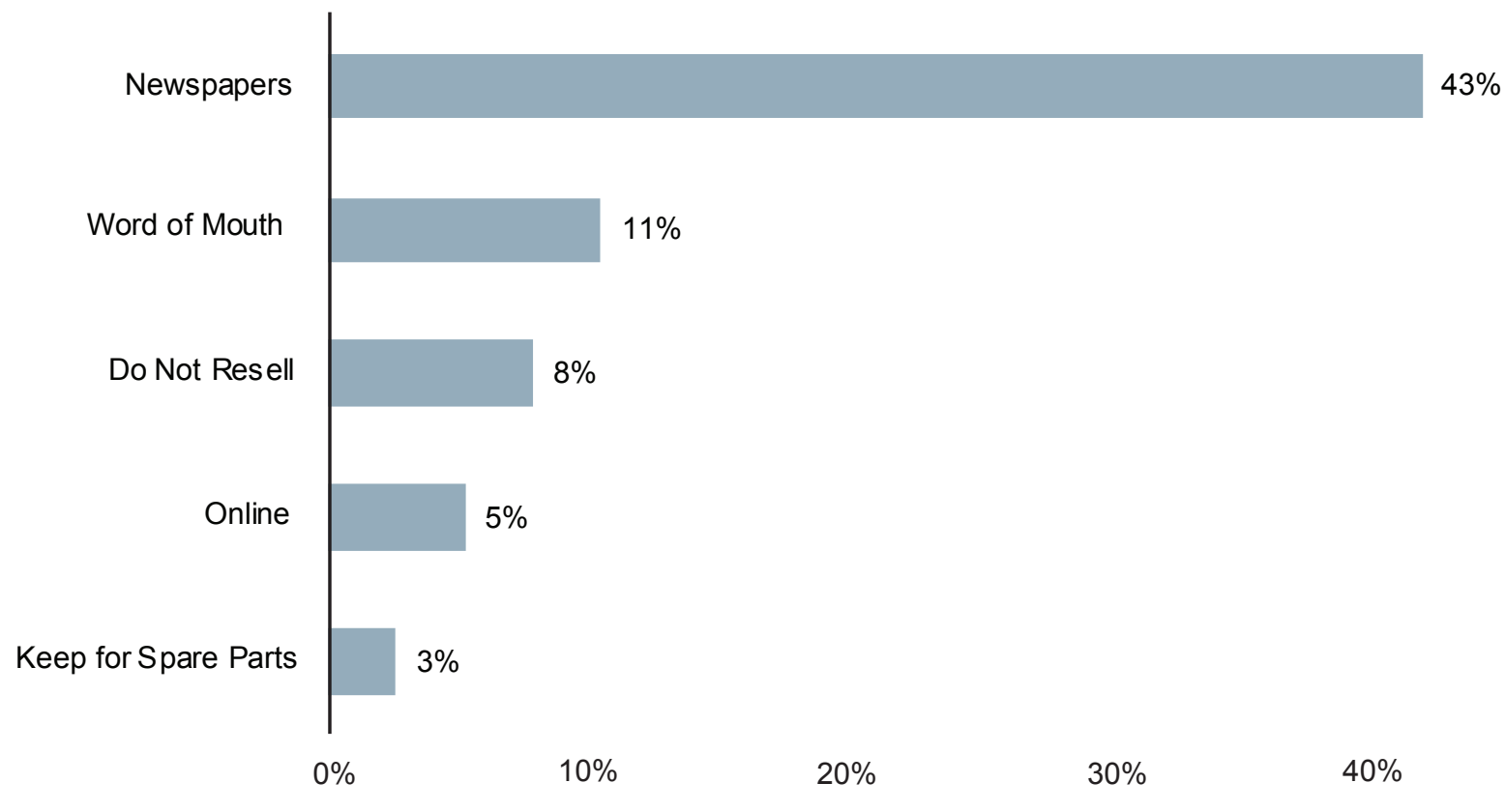

$50 \%$

\subsection{Responses from Lenders' Survey}

Respondents to the lenders' survey included microlending institutions (38 percent), cooperatives and credit unions ( 25 percent), commercial banks (13 percent), and state-owned banks and government agencies (10 percent). (See figure 19.)

\section{Figure 19: Survey of Lenders}

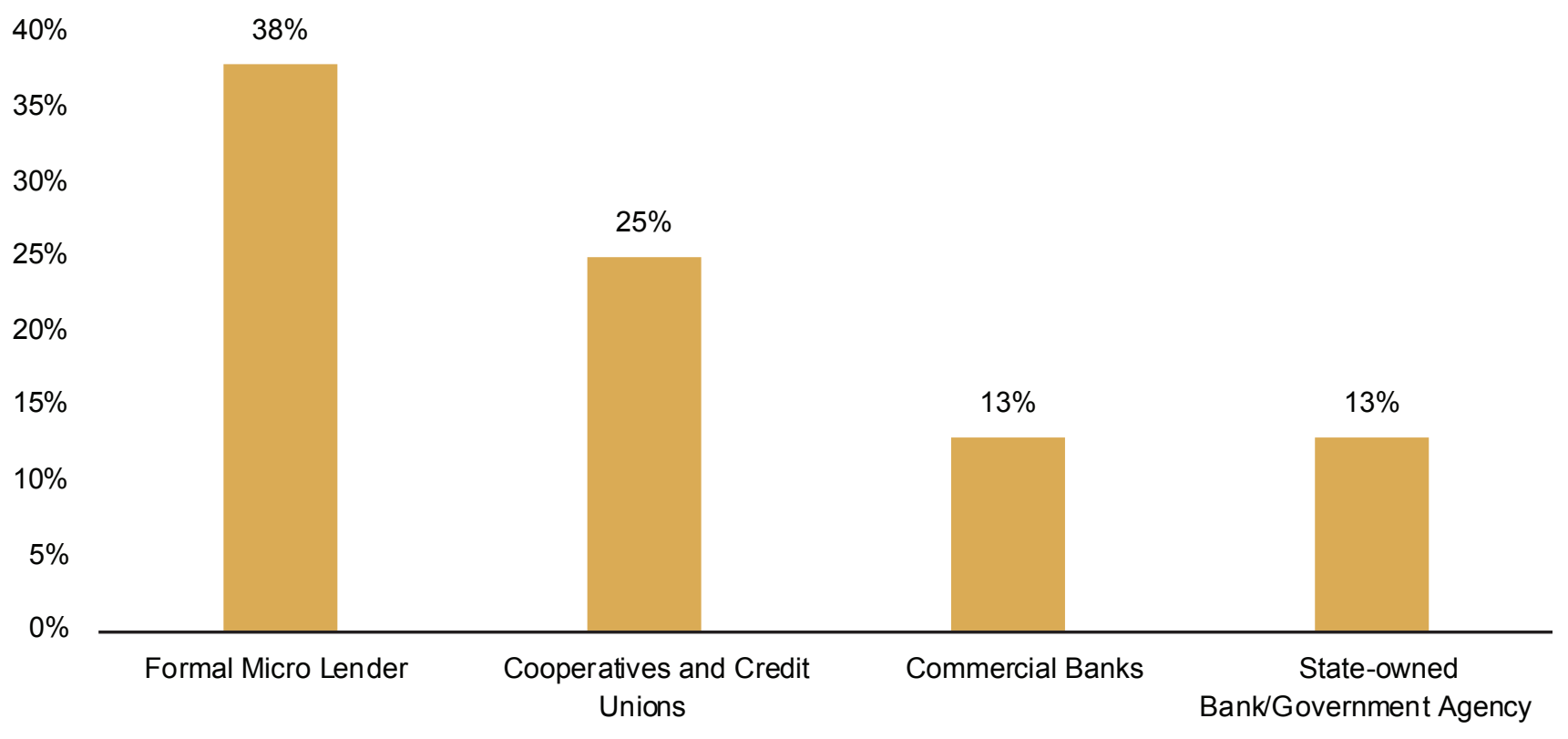


Table 2 showcases the ranking of movable assets. Lending organizations considered motor vehicles to be the assets used most frequently as collateral and also one of the most acceptable forms of collateral. On the other hand, crops and intellectual property rights were ranked lowest among movable assets, while machinery, office equipment, inventory, and accounts receivable were accepted by some financial institutions but with supplementary funding or collateral requirements.

\begin{tabular}{|c|l|c|}
\hline & Asset Type & Average Rank \\
\hline 1 & Motor Vehicles & 1 \\
\hline 2 & Land and Building & 2 \\
\hline 3 & Securities & 3 \\
\hline 4 & Accounts Receivable & 4 \\
\hline 5 & Machinery & 4 \\
\hline 6 & Inventory & 5 \\
\hline 7 & Office Equipment & 5 \\
\hline 8 & Crops & 6 \\
\hline 9 & IP & 7 \\
\hline
\end{tabular}

Figure 20: Rating of Collateral Assets

100

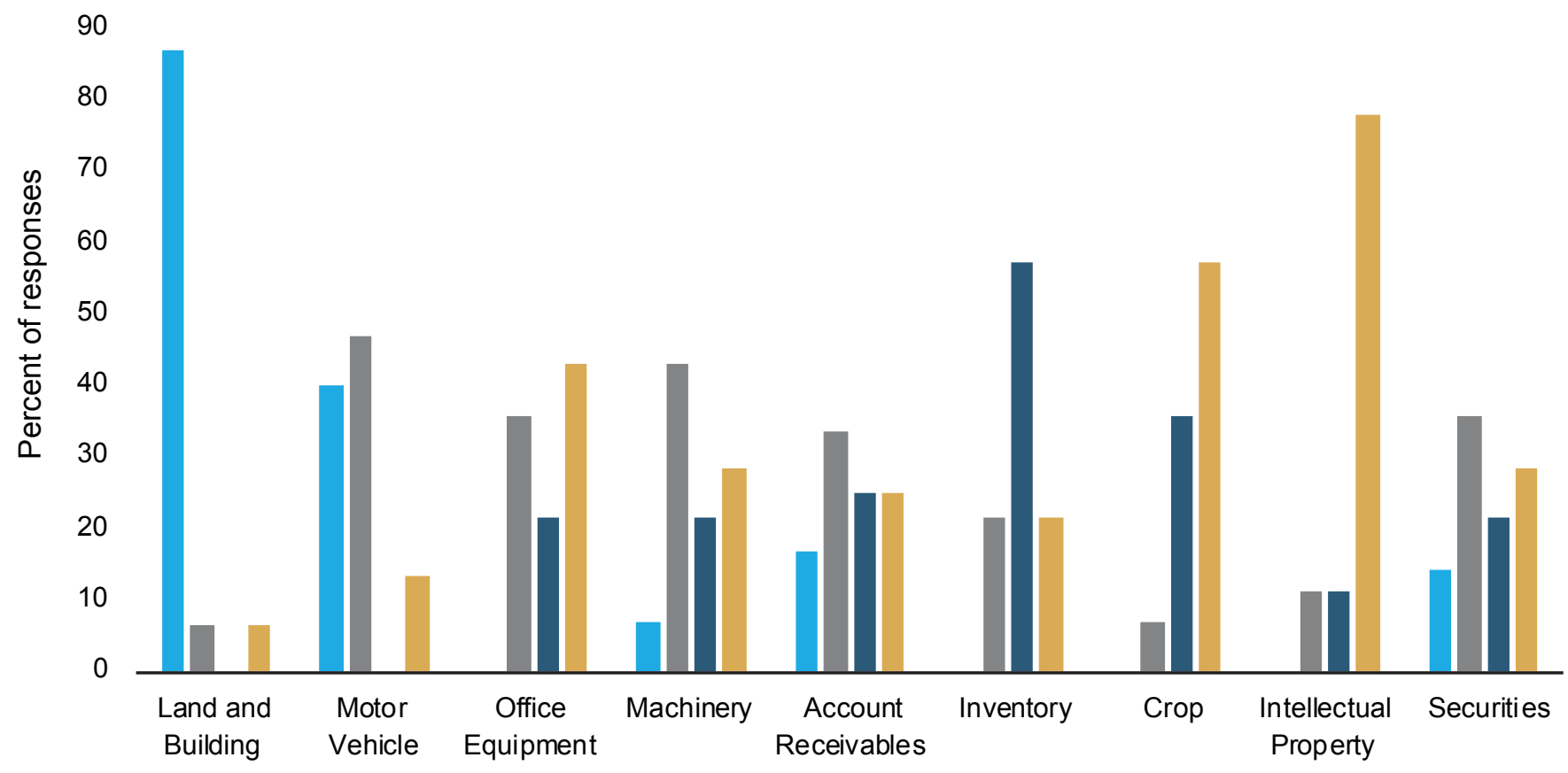

$\square$ Highly acceptable $\quad$ Acceptable $\quad$ Considered only with supplementary $\quad$ Not considered by Institution 
Of the total of 82 respondents, approximately 57 percent were manufacturers, 25 percent were classified as agroprocessors, and 18 percent were lending organizations. A total of 76 percent were small and medium enterprises, while 24 percent were large firms.

In terms of valuation of assets paid, valuators were the most common source of valuation of movable assets, particularly motor vehicles. However, valuation was also obtained by information gathered from online sources, classified ads, and personal experience (figure 21). Specifically, paid valuators were the most common means used to value motor vehicles. Online sources were the main means used to value most of the other movable assets. On the other hand, personal knowledge was used primarily to value field crops and accounts receivable.

\section{Figure 21: Valuing Movable Assets}

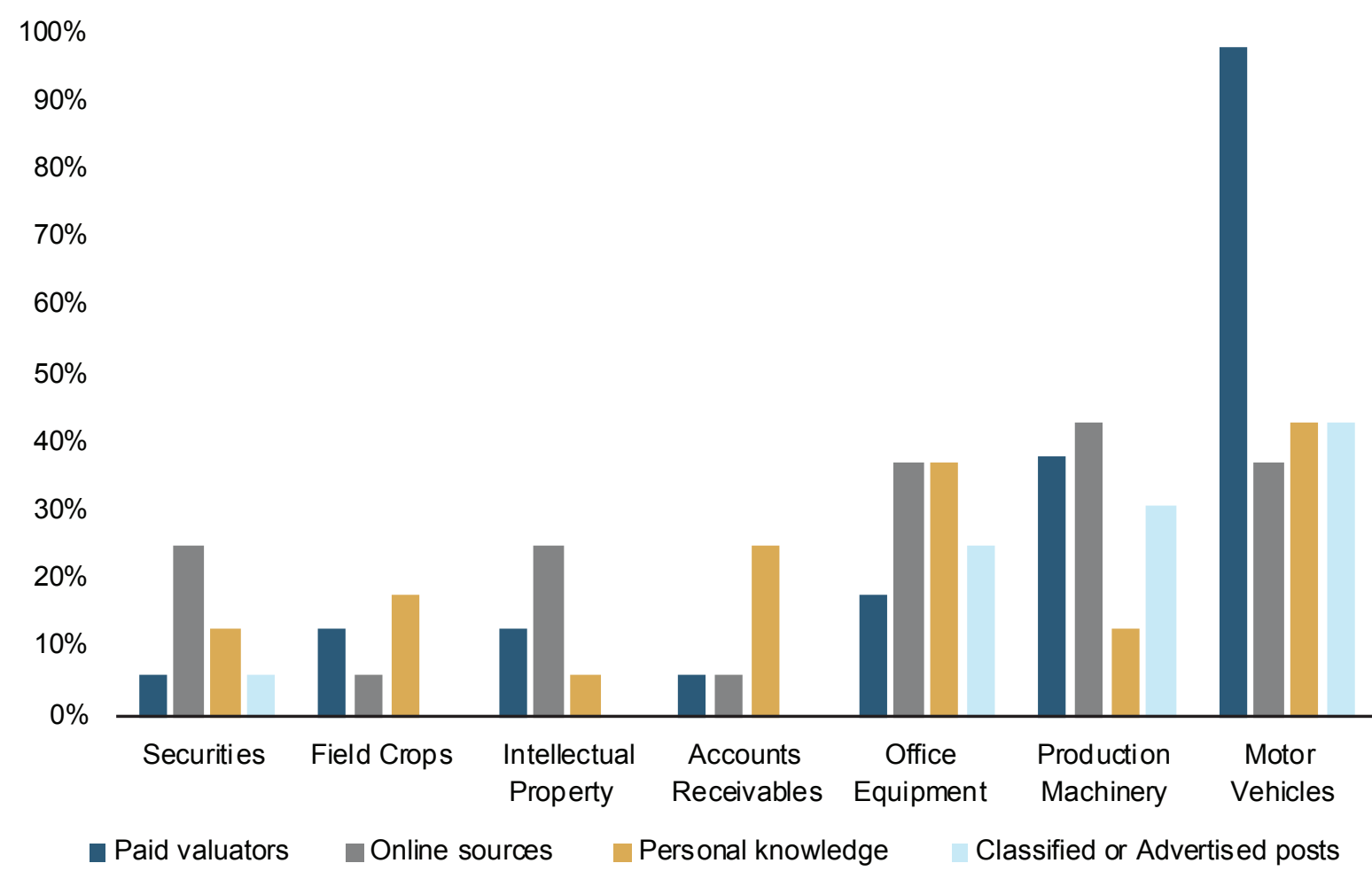

Figure 22: Market Dynamics of Movable Assets

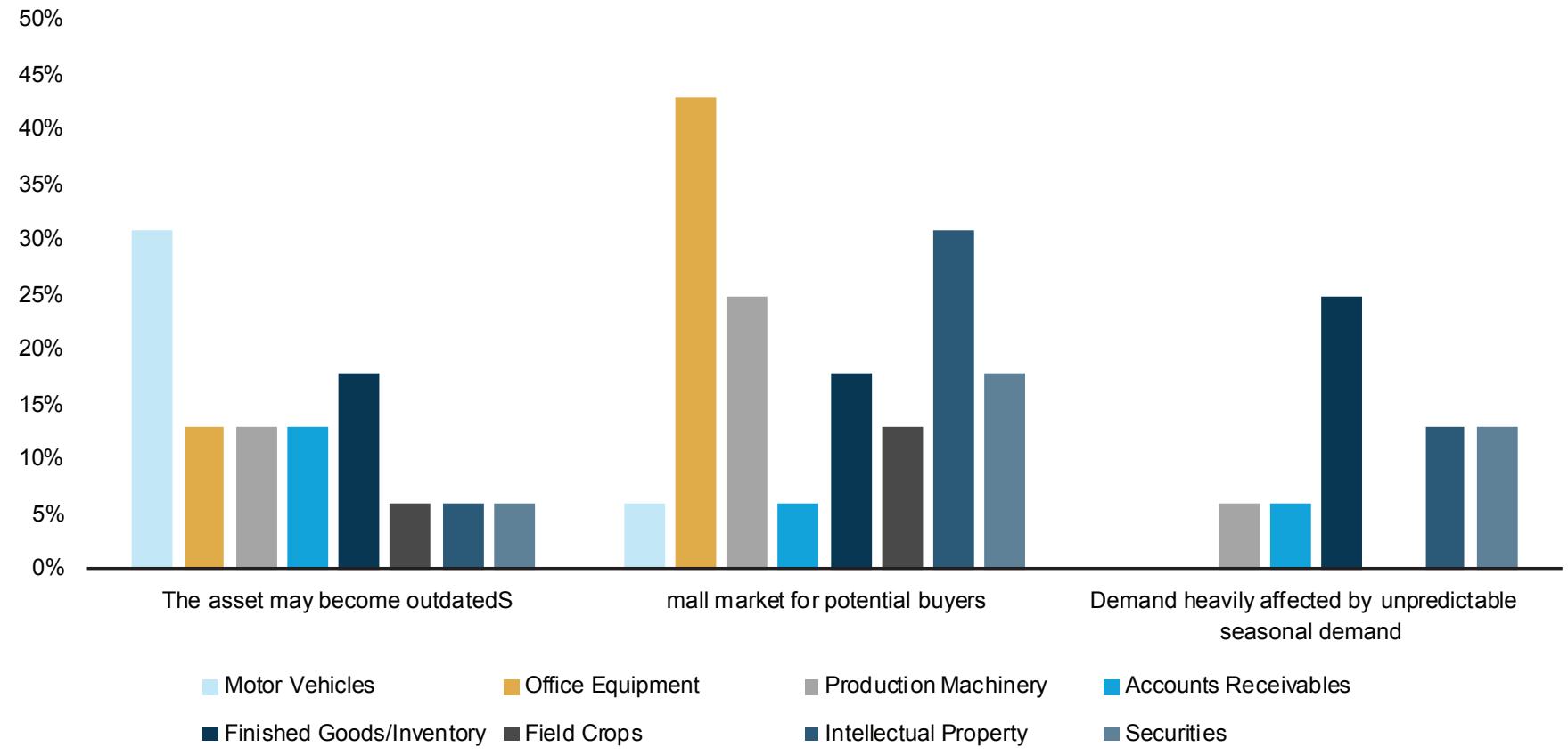


Motor vehicles and inventory were considered the two assets most likely to be outdated over time in the open market (figure 22, panel A). Secondary markets for office equipment, production machinery, and intellectual property were considered to be much more limited relative to such assets, supporting previous results highlighting the relative difficulty in disposing of these assets (figure 22, panel B).
Finally, finished goods/inventory, intellectual property, and security-based assets were most affected by seasonality in market demand (figure 22, panel C). Collectively, this supports the relative importance of motor vehicles as critical assets that can be used as collateral in movable-asset financing.

Figure 23: Channels Used Most Frequently to Dispose of Movable Assets by Lenders

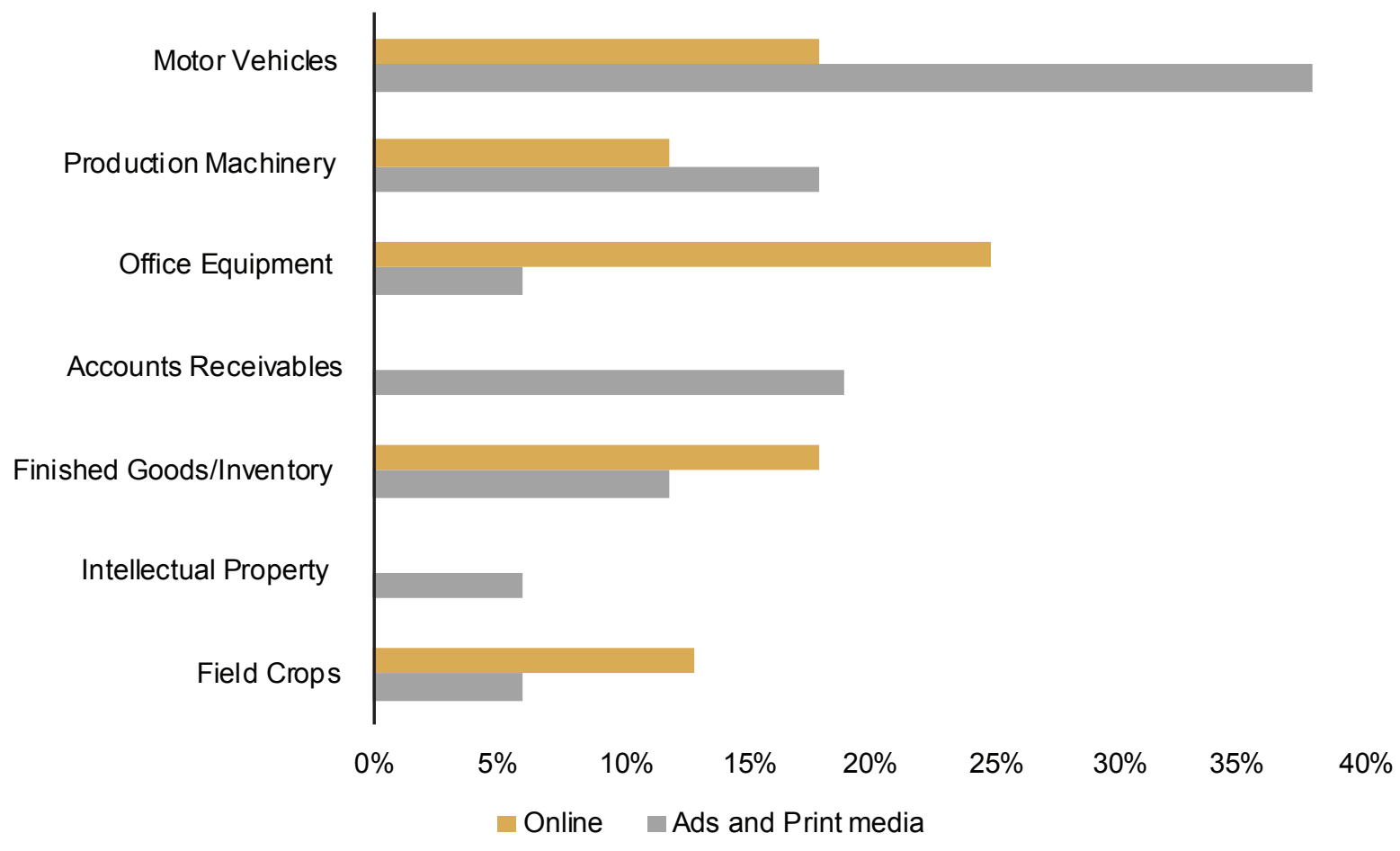

Advertisements, classified ads, and online tools were common channels used to dispose of movable assets by lending agencies. However, online portals tended to be used more frequently to dispose of office equipment, finished goods, and crops, while ads and print classifieds were used primarily in the case of motor vehicles, machinery, and accounts receivable ${ }^{9}$ (figure 23).

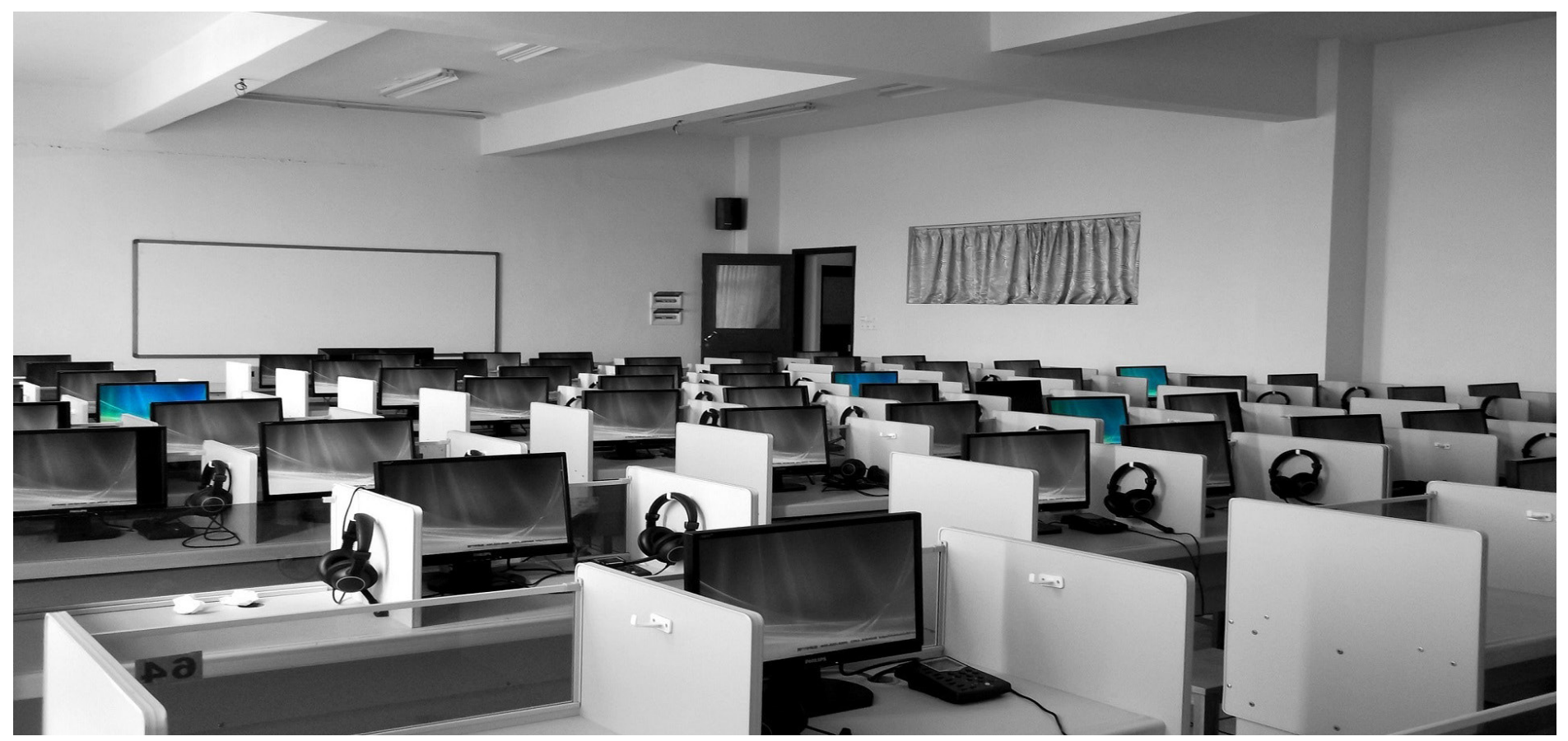




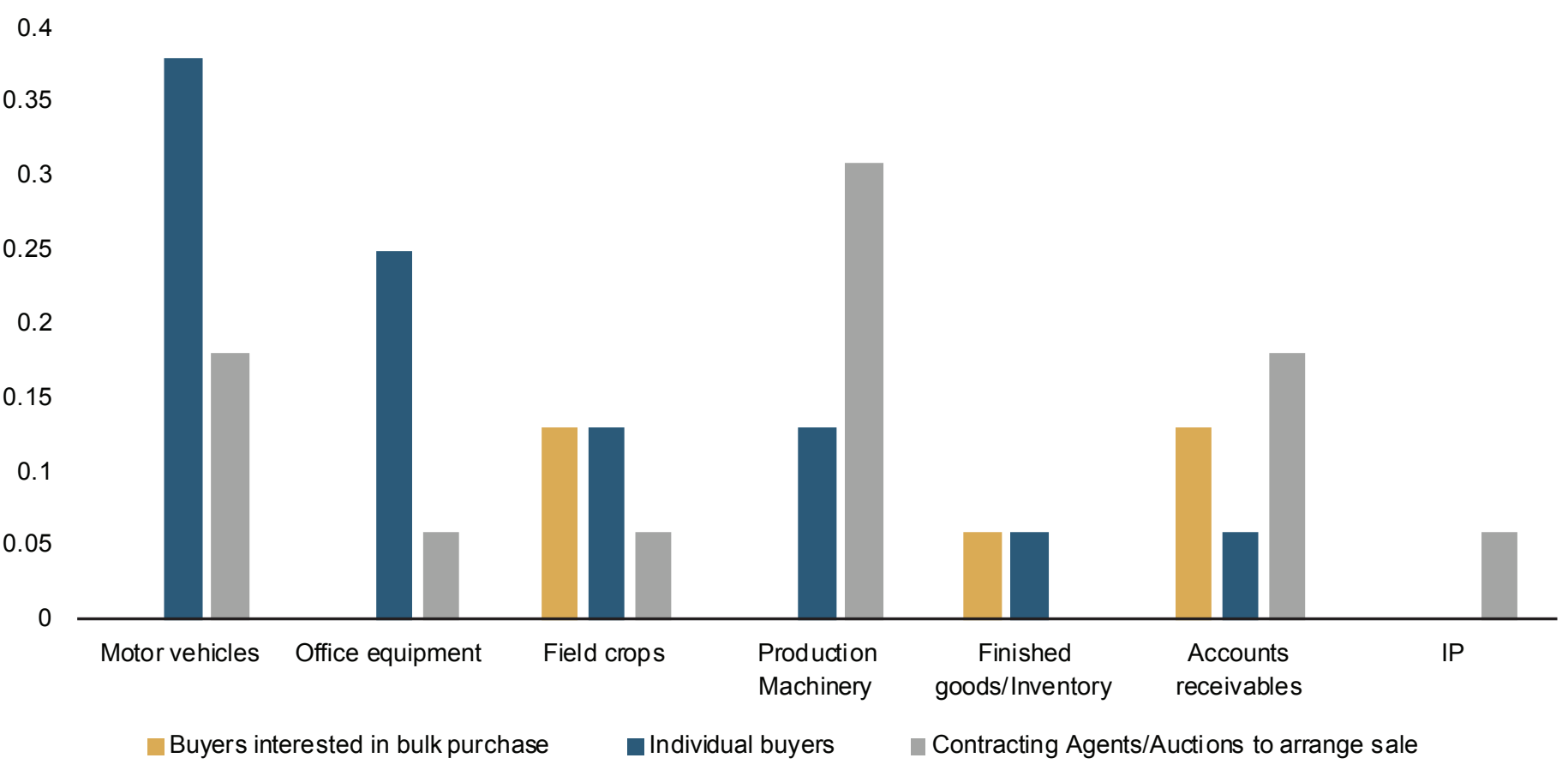

Finally, in terms of buyers of movable assets, individual motor vehicles and office equipment, while auctions were buyers, bulk buyers, and auctioneers were the most frequent more suited for the disposal of machinery and accounts buyers of movable assets sold by lenders. However, receivable (figure 24). individual buyers appeared to be more willing to purchase 


\subsubsection{Market Informality and Fragmentation}

Feedback from mission interviews indicated that the secondary market for movable assets possessed the following characteristics:

- Fragmentation: Insights from the survey data show that lenders are of the view that the potential market for key movable assets remains small (that is, office equipment and production equipment). This assumption is so pronounced that it is common for manufacturers (1) to store unused equipment as spare parts, and (2) to sell the equipment as scrap metal. ${ }^{10}$

However, feedback from the focus groups indicated that both lenders and manufacturers may seek the sale and purchase of used movable assets from similar categories of traders. For instance, a manufacturer may visit a usedequipment dealer that is located nearby. Likewise, a separate manufacturer may also be interested in a similar piece of equipment and may visit a similar but unrelated trader (without being aware that a wider pool of traders exists). While the category of trader is similar, the two operate in fragmented spaces. This fragmentation creates enclaves that effectively restrict the depth of the market and create liquidation challenges for assets that otherwise may have significant aggregate supply and demand.

- Degree of informality in trading: Empirical insight from both the field interviews and survey data indicate that manufacturers leverage their informal network when purchasing or liquidating movable assets-for instance, relying on word of mouth or recommendations from other manufacturers.

This brings to the forefront the following two issues, which have restricted MABL in Jamaica:

High discounting: Without a robust network of valuation expertise for key movable assets, lenders frequently resort to internalizing the valuation process by leveraging incompany resources to establish the value of movable assets. These duties are sometimes performed using methodologies that may rely heavily on anecdotal evidence (for example, personal knowledge). Being aware of this constraint, lending institutions are inclined to discount the value of the movable asset heavily. This can sometimes result in the following two outcomes:

- The manufacturer becomes unable to access the requested capital owing to low valuations on the movable asset.

- The manufacturer may be forced to pledge multiple pieces of movable assets to meet the required collateral value. In such instances, the lenders may opt to refuse lending due to the higher transaction costs associated with accepting multiple pieces of movable assets as collateral.

Bank of Jamaica concerns: BOJ had a list of acceptable collateral in the past. This listing of acceptable collateral existed within the draft Credit Classification, Provisioning, and Non-Accrual Regulations. To give banks more room to utilize movable assets, BOJ in 2019 issued its Standard of Sound Practice on Problem Asset Management, Provisioning Requirements and Accounting for Expected Credit Losses, in which the bank introduced a principles-based approach to the assessment of the collateral.

This principle-based approach encompassed the following three core principles:

1. Legal certainty over the arrangements

2. The market price or objective price of the collateral

3. The presence of the market - that is, having (i) a primary market and (ii) a secondary market for collateral

For BOJ to determine if these principles are met, the relevant information must be provided. The lack of a robust valuation network will challenge banks when meeting the requirements for the second principle - and the possibility for capital relief for nontraditional collateral. 


\section{Movable Asset}

Accounts receivables

Movable production machinery

Finished goods

Office equipment

Field crops

Intellectual property

\section{Valuation Mechanism Reported}

Face value of receivables and personal knowledge to assess the creditworthiness of the receivable firm

Some existence of a narrow professional valuation network coupled with online sources or old classified and advertisement posts

Personal knowledge and online sources

Online sources or old classified and advertisement posts

Rarely considered

Rarely considered

\subsubsection{Uncertainty and the Emphasis on Determining Anticipated Success}

The uncertainty of estimating the secondary-market potential for movable assets is affecting lenders' estimation of risk. An immediate outcome is one where lending institutions are forced to overemphasize the likely success of the investment project (or reason for financing). In the presence of poor secondary-market and valuation options, financial institutions have opted to place greater emphasis on determining the ex ante success of the business proposal. This included 50 percent of the survey respondents considering sound business plans ${ }^{11}$ as essential components of the loan application. Likewise, 88 percent deemed financial statements, cash-flow projections, and evidence of historical performance as mandatory for loan applications.

Even so, in interviews, key stakeholders frequently flagged these elements as weakest for MSMEs - especially those that operate with a high degree of informality. 
The COVID-19 pandemic of 2020 has been an unexpected global event that continues to create great shock and displacement. Worldwide there have been over 4.2 million infections and close to 300,000 deaths. ${ }^{12}$ In addition to the devastating loss of lives and overwhelmed medical facilities, there is continuing severe economic fallout arising from the lockdown and social-distancing measures (among others) that the governments of most countries have instituted as the first line of defense to flatten the curve of this pandemic.

Like every other country, Jamaica has had to implement immediate emergency measures to combat the threat to its citizens and residents' lives and general public safety, while developing strategies to navigate both short- and long-term economic recovery. Estimates as of May 11, 2020, show that Jamaica has registered 505 cases of coronavirus infections and nine deaths. This section of the report attempts to put into context how the growth of MABL in Jamaica can be affected amid the uncertainty surrounding the coronavirus. It also analyzes the strategies being used to combat the pandemic and some foreseeable challenges ahead for the constituents most likely to bear the brunt of the economic fallout. Uncertainty is the keyword here, and its relevance is seen by how quickly so many things have changed and are expected to change further.

\subsubsection{Scope and Trends of the Coronavirus Pandemic}

The COVID-19 pandemic is expected to last for two years or at least 18 months (which is the time commonly estimated to develop an effective vaccine against the coronavirus.) According to the Center for Infectious Disease Research and Policy at the University of Minnesota, close to $60-70$ percent of the world's population is also expected to be infected throughout this pandemic. There is still no scientific proof or consensus that any sort of herd immunity will occur, although that's the hope and expectation of some experts. ${ }^{13}$

As most of the world has done, Jamaica has closed its borders to international visitors until further notice. Combined with restrictive stay-at-home orders (with exceptions for access to essential services) and social-distancing rules, the adverse impacts on such important sectors of the economy as tourism, manufacturing, and agri-business, among other areas, cannot be exaggerated. In a very recent study of 66 emerging countries' financial strength published by The Economist, Jamaica ranked 56th. ${ }^{14}$ This could pose some liquidity issues for the Government of Jamaica, which will have much increased fiscal responsibilities in providing financial resources for public health and safety, as well as providing pandemic monetary relief to its citizens.

In the best of times, access to financing, especially from the formal banking institutions, has been very difficult for most of the targeted constituents. Even when there is some access, the costs of compliance and repayment are challenging. MABL has been positioned to fill that gap. Lockdowns utilized to flatten the curve come at steep economic costs. These costs are characterized by the high unemployment, lower wages, and restricted access to credit that result from the stay-at-home features accompanying the various lockdown strategies. Lockdowns have a disproportional effect on MSMEs, which typically lack access to the credit needed to bridge this undefined period of loss to stage any type of recoveries.

In the United States, it is estimated that among lower-wage earners, 35 percent of people lost their jobs within six weeks. A working paper by Chicago's Becker Freidman Institute showed that correspondingly only 9 percent of the highestwage earners lost their jobs. ${ }^{15}$ The downturn associated with the coronavirus pandemic is falling very unequally across wage earners. ${ }^{16}$ This trend is expected to be seen in most countries, with Jamaica being no exception. Lowestwage workers, entrepreneurs, and MSMEs will be among the constituents most exposed to the COVID-19 pandemic, and many may find it especially difficult to access timely relief from either governmental or financial institutions. The Government of Jamaica can use this opportunity to highlight and promote MABL as a priority recovery strategy. The government could utilize a combination of direct relief to affected constituents, such as the manufacturing and agri-business sectors, while providing prudent incentives, partnerships, and leadership to the banks and other financial institutions to meaningfully increase the use of MABL products and platforms to alleviate any anticipated credit crisis.

In the delicate balancing act between public health and safety and economic recovery, governments face the risk of reopening the economy too soon without adequate safeguards. Lifting lockdown measures too early can lead to a feared second wave of infections, further jeopardizing any economic recovery in the process. This was the experience of Hokkaido, ${ }^{17}$ an island in the northern region of Japan that was cited as an early model of how to control the spread of the coronavirus disease. Hokkaido, with a population of 5.3 million people, first suffered an outbreak in February after its annual Sapporo Snow Festival, which attracted over two million visitors. After their lockdown mitigation measures seemed to be working, they reopened the city in March only 
to suffer a new wave of infections, leading the city to be shut down again. ${ }^{18}$ In Wuhan, China, where it is believed that the coronavirus originated, the city was locked down for 76 days. Officials project that economic growth and production would be painfully slow, estimating that after three years, the economy will still be hurting. The government in Wuhan has implemented a rent-free program as one of its short-term strategies; businesses leasing from state-owned enterprises pay no rent for three months. ${ }^{19}$
Driven principally by the stay-at-home orders instituted by governments worldwide, the COVID-19 pandemic has accelerated the trend of working remotely. The use of Zoom has skyrocketed as employers instituted work-from-home delivery platforms where applicable, and all indications are that this may be one of the enduring legacies of the coronavirus-induced crisis. However, there must be digital platforms and infrastructure for remote work to be practicable and efficient. The Caribbean region is arguably less than ready to operate meaningfully in a digital environment. It was given a rating of 5 out of 10 by Therese Turner-Jones, the general manager of the Inter-American Development Bank's Caribbean Country Department. ${ }^{20}$ Here could be a great opportunity for the Government of Jamaica to take the lead, working with the Jamaican banks and other financial institutions to create the digital platforms and products in the financial-technology space for online delivery of services for banking and other suitable transactions. 


$$
5+c_{-1}
$$

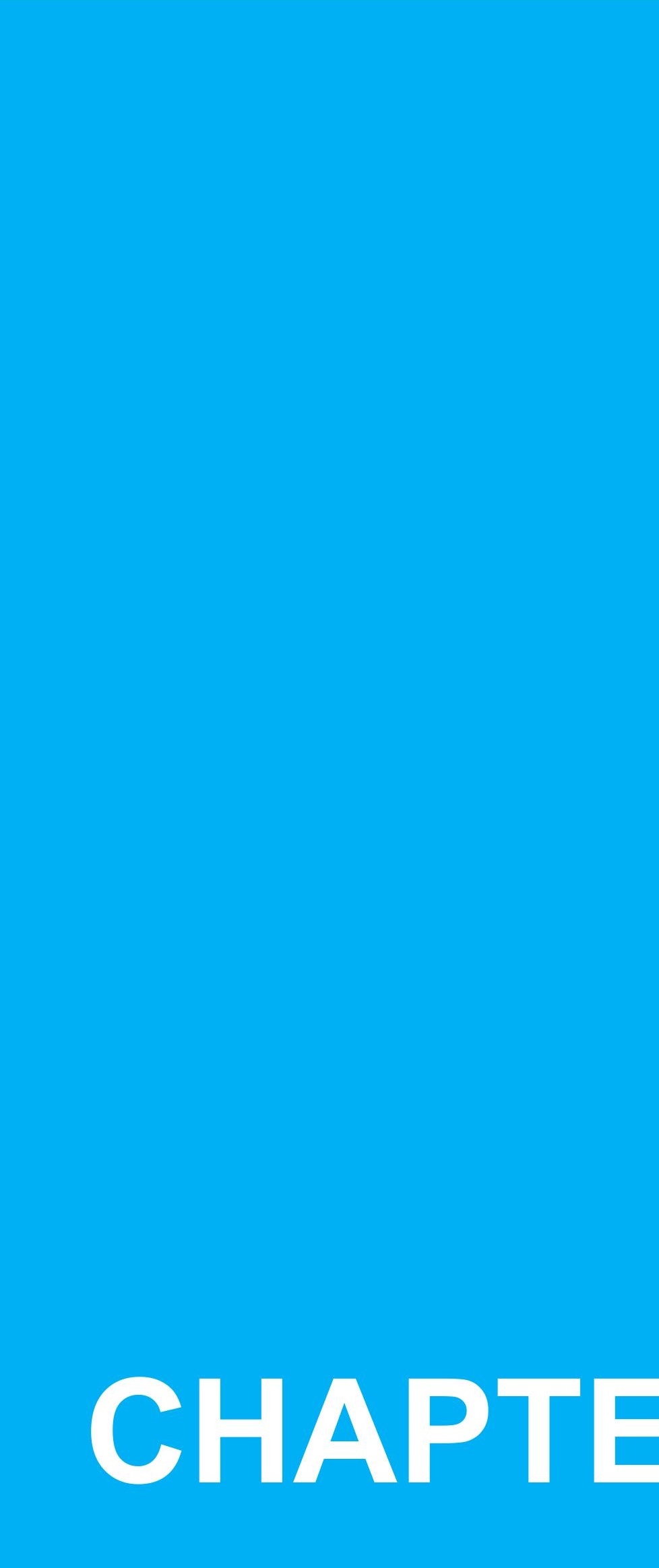

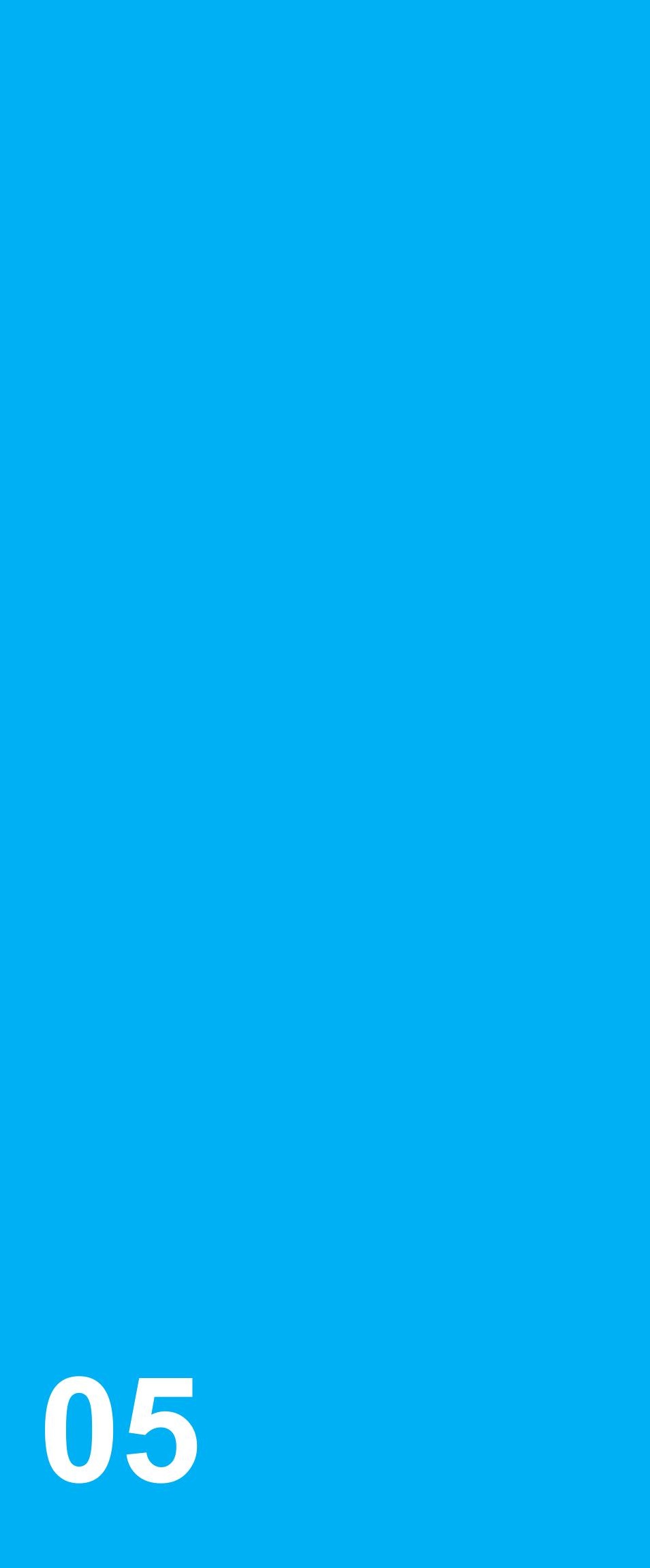




\section{CHAPTER 05}

\section{Summary Analysis of Key Secondary Markets in Jamaica}

Several secondary markets exist in Jamaica. These markets take many forms depending on the type of movable asset, the buyers and sellers' level of sophistication, and the overall formality and institutional support provided to facilitate transactions on these markets. Newspaper classified ads, dealerships, and online platforms continue to dominate in terms of both sourcing and disposal of secondhand assets. However, formal and informal associations and "word of mouth" relationships also play critical roles in both the sourcing and disposal of assets. Motor vehicles, movable machinery, and office equipment are the most commonly traded assets on these markets. In some instances, persons may also choose not to dispose of assets, keeping assets for spare parts or dumping where necessary.

Inopportunely, many market channels provide only very basic functionalities, focusing on listing details of items for sale and bringing buyers and sellers together. Other value-added services, such as valuation of assets, facilitating payments, and shipping of assets, are not included. For instance, it is relatively easy to provide a brief description of the asset on these platforms. This may be a contributing factor in terms of the types of assets that are frequently traded through these channels, as is the continued importance of informal network relationships to facilitate transactions. Specifically, informal networks can facilitate the exchange of private information in terms of the quality of assets, while reputation effects can insulate against the offer of poor-quality products or services for sale.

It should be noted that several online solutions exist to facilitate the trade of secondary assets. Platforms include a mix of local and international online marketplaces, where persons can sell various items based on category. ${ }^{21}$ These existing online marketplaces usually lack professional valuations, but images of the items are usually included and a rating system is in place for both the seller and the product. Additionally, not all online marketplaces facilitate online payments or carry a history of transactions completed on the platforms. More recently, the Government of Jamaica took steps to establish the online Agri-Linkages Exchange (ALEX). (See the accompanying case study for a breakdown of the platform.) This platform was set up to facilitate the purchase and exchange of crops between farmers and buyers within the hotel industry. The overarching aim of the platform was to leverage technology to bring hoteliers in direct contact with farmers to retain more of the economic benefits of tourism in Jamaica, since there is an opportunity to present a reliable supply of "high-quality" produce yearround to customers. While ALEX deals specifically with produce and agricultural items, this platform can be seen as an example not only in terms of functionalities but also in terms of experience developing an online market solution for movable assets.

Table 4 highlights the frequency of movable assets being sold, their use as collateral, lending opportunities for these assets, and the secondary markets in which the assets can be found. 


\begin{tabular}{|c|c|c|c|c|}
\hline Asset & $\begin{array}{l}\text { Used as } \\
\text { Collateral } \\
\text { Locally }\end{array}$ & Frequency & $\begin{array}{l}\text { Lending Options } \\
\text { Locally }\end{array}$ & Current Secondary Markets \\
\hline $\begin{array}{l}\text { Agricultural } \\
\text { products, } \\
\text { particularly high- } \\
\text { value-added } \\
\text { products such as } \\
\text { cocoa and coffee }\end{array}$ & Yes & Medium & Credit advances & $\begin{array}{ll}\text { - } & \text { ALEX } \\
\text { - } & \text { Local marketplaces } \\
\text { - } & \text { International exports }\end{array}$ \\
\hline Inventory & Yes & Medium/low & Credit advances & $\begin{array}{l}\text { - None, used mainly as collateral and to ensure } \\
\text { repayment (typically not collected and resold) }\end{array}$ \\
\hline $\begin{array}{l}\text { Accounts } \\
\text { receivable }\end{array}$ & Yes & Medium & $\begin{array}{l}\text { Factoring } \\
\text { Reverse factoring }\end{array}$ & $\begin{array}{l}\text { - None, but steps are being taken to create an } \\
\text { online platform to facilitate factoring }\end{array}$ \\
\hline Motor vehicles & Yes & High & $\begin{array}{l}\text { Short-term credit } \\
\text { Financial leases } \\
\text { Operating } \\
\quad \text { leases }\end{array}$ & $\begin{array}{l}\text { - } \text { Newspaper ads } \\
\text { - Used-car markets } \\
\text { - } \quad \text { Car auctions } \\
\text { - } \quad \text { Yard sales https://jamaicaclassifiedonline.com/ } \\
\text { - } \quad \text { Loan sharks and pawnbrokers } \\
\text { - Jamaican classified https://www.jappclassifieds. } \\
\text { com/ } \\
\text { - Jam deals http://www.jamdeal.com/browse/ } \\
\text { - } \quad \text { Coatured } \\
\text { - Cool deals https://www.coolmarket.com/ }\end{array}$ \\
\hline Equipment & Yes & Medium & $\begin{array}{l}\text { - Short-term } \\
\text { credit } \\
\text { - } \text { Financial } \\
\text { leases } \\
\text { Operating } \\
\text { leases }\end{array}$ & $\begin{array}{l}\text { - Informal business networks that facilitate the } \\
\text { sale of assets } \\
\text { - Facebook marketplace } \\
\text { - } \text { Amazon and eBay } \\
\text { Individual buyers }\end{array}$ \\
\hline $\begin{array}{l}\text { Intellectual } \\
\text { property }\end{array}$ & No & Low & Limited usage & - None \\
\hline Furniture & Yes & $\begin{array}{l}\text { Medium/ } \\
\text { high }\end{array}$ & Short-term credit & $\begin{array}{l}\text { - Facebook marketplace } \\
\text { - } \quad \text { Lard sales https://jamaicaclassifiedonline.com/ } \\
\text { - Jamaican classified https://www.jappclassifieds. } \\
\text { com/ } \\
\text { - Jam deals http://www.jamdeal.com/browse/ } \\
\text { featured } \\
\text { - Cool deals https://www.coolmarket.com/ }\end{array}$ \\
\hline $\begin{array}{l}\text { Jewelry and other } \\
\text { forms of movable } \\
\text { assets }\end{array}$ & Yes & Medium & Short-term credit & $\begin{array}{l}\text { - Yard sales https://jamaicaclassifiedonline.com/ } \\
\text { - Loan sharks and pawnbrokers } \\
\text { - Jamaican classified https://www.jappclassifieds. } \\
\text { com/ } \\
\text { Jam deals http://www.jamdeal.com/browse/ } \\
\text { featured } \\
\text { - Cool deals https://www.coolmarket.com/ }\end{array}$ \\
\hline
\end{tabular}




\subsection{Case Study: Agri-Linkages Exchange (ALEX) Platform}

One of the central aims is to look at the options that presently exist for developing secondary markets for movable assets. The ALEX platform was set up to facilitate the purchase and exchange of goods between farmers and buyers within the hotel industry. The overarching aim of the platform was to leverage technology to bring hoteliers in direct contact with farmers to retain more of the economic benefits of tourism in Jamaica, since there is an opportunity to present a reliable supply of "high-quality" produce year-round to customers. While ALEX deals specifically with produce and agricultural items, this platform can be seen as an example not only in terms of functionalities but also in terms of experience developing an online market solution for movable assets.

\subsubsection{The Platform}

The platform was initiated in late 2018, and the original website underwent revision in 2019. Generally, the platform hosts registered farmers' stores for marketing purposes. The platform requires farmers to register to utilize the services offered by ALEX.

\subsubsection{How the System Works}

Registration process: Officers from the Jamaica Agricultural Marketing Information System survey the market and develop a price range in different parts of the country to establish a "price band" that farmers can use for advertising their products.

Registration can take place in two ways: Farmers can register either online, via the website, which can be accessed by computer or cellphone, or call in, in which case an officer will complete the registration process for them. All farmers who wish to utilize the ALEX platform must be registered with Rural Agricultural Development Authority (RADA) as legitimate farmers. Farmers who are registered are assigned a number that works as a personal ID.

The farmers and officers or coordinators will be in direct contact with each other. Farmers will notify the coordinators about the availability of their produce. The coordinators, in turn, will update information on the platform about the produce and cost. They can also link farmers with potential buyers.

Transactions: Actual transactions are not presently being done directly through the site. The officers or coordinators can prepare and manage invoices on behalf of the farmer. Invoices can be generated and sent to the buyer so that they know the actual cost of the transaction.
Quality control: Extension officers carry out site visits to farmers prior to the crop being reaped to ensure the quality of the produce. Extension officers are assigned to different districts or zones around Jamaica. Presently, there is one officer per district. Due to the limited number of extension officers, there is a focus on larger farms, and visits to farmers often have to be strategically planned to get the most out of the site visits. Marketing brokers are also utilized. Brokers liaise with farmers to source products and find out what is available for sale. If a specific crop is in demand, brokers reach out to officers and farmers. Information about when the crop is grown and which farmer would be able to help is provided. Marketing officers can also assess produce for quality control. It is hoped that this exercise will be done more frequently, perhaps along with coordinators.

Additionally, through RADA, farmers are offered training programs that will assist them with quality control in the long term. RADA trains the farmers on produce handling and selection, assisting them in reducing losses in future sales.

Transportation and storage: No warehousing, storage facility, or transportation service is offered by ALEX, but the platform's sister organization, Agro Investment Corporation, offers warehousing services as well as processing, packaging, and exporting services to those who require it. Farmers are required to pay for these services.

\subsubsection{Challenges}

- Online transactions: Actual transactions are not presently done through the site. Transactions are made directly between the buyer and the farmer. Once the transaction is completed, the information is updated on the platform by the officers or coordinators.

- Payments: Sometimes farmers are not paid fast enough. Since they are unwilling to commit to a buyer if payments are delayed, some farmers are hesitant to register for the platform. The farmers prefer persons who can pay up front or very fast, as they need the money to put back into their operations.

- Platform usage: A general observation, even prior to the onset of COVID-19, was the need to increase usage by hoteliers. Other "big buyers" peruse the platform but still prefer to call in, rather than $\log$ in, to the site. It is expected that these entities need more time to adapt to the platform and its features. 


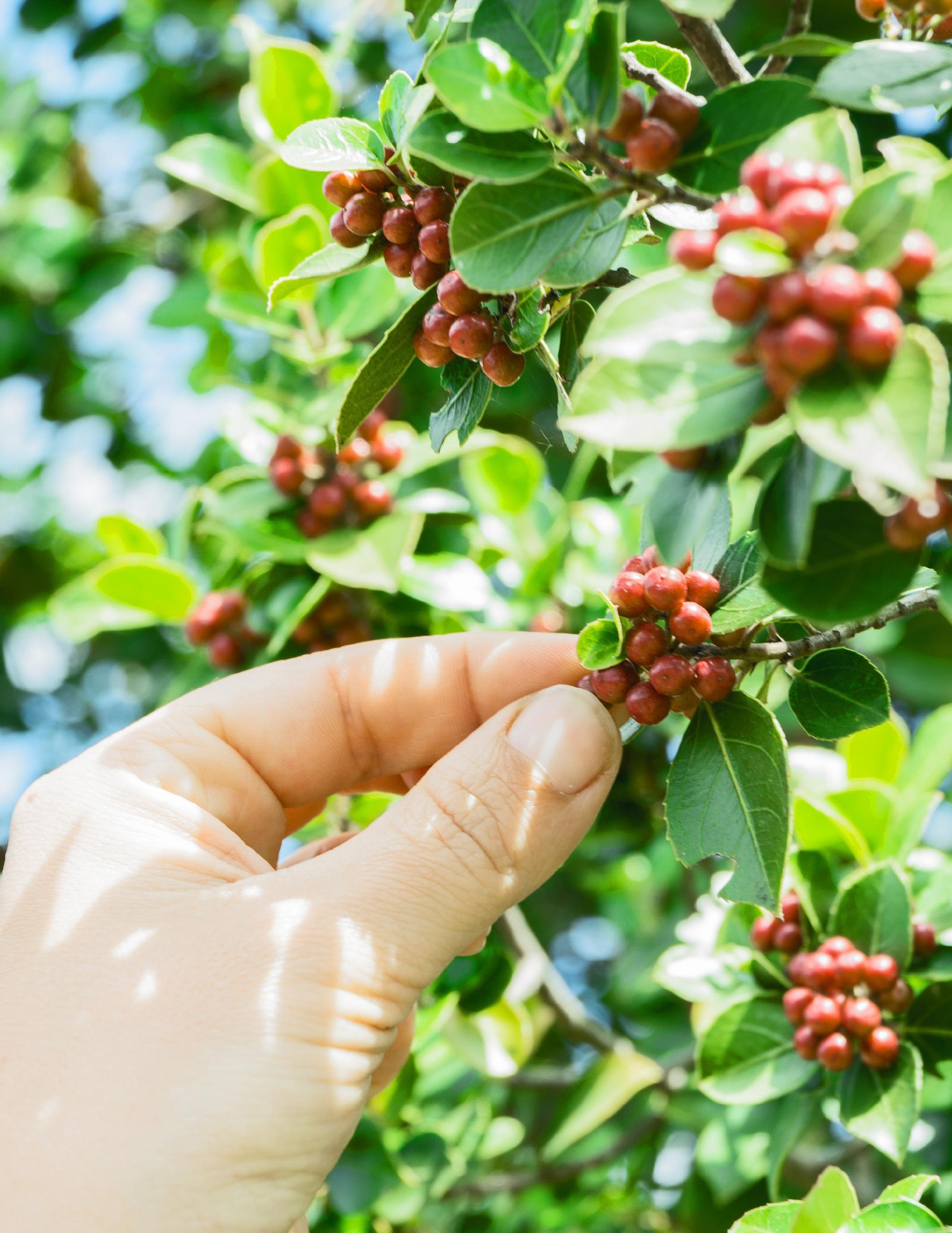




\subsubsection{Opportunities}

- Financing: Communications are underway with DBJ to assist with the implementation of a financing system to create a credit footprint or enhance creditworthiness for farmers. Discussions are also taking place to assist with the development of reverse-factoring options for farmers who sell their crops to larger, more-established entities. This solution will enable a faster turnaround for farmers when assessing working-capital financing, and it will also act as an incentive for more farmers to register on the platform. 

(n) 


\section{CHAPTER 06}

\section{Final Recommendations}

MABL in Jamaica continues to be on the rise. One key element in the framework for MABL is secondary markets. Secondary markets facilitate the disposal and trade of movable assets, updated market-based valuations, and historical information for secondhand assets. Secondary markets for movable assets exist in Jamaica, but they are mainly fragmented and based on traditional means, such as newspaper advertisements, physical auctions, and informal word-of-mouth channels. Online portals do exist. Apart from bringing buyers and sellers together and providing a brief description of the assets, however, many of these channels offer very limited value-added services, such as valuations and payments that can support decision making and the completion of transactions. Additionally, because of these factors, few assets are commonly traded in these secondhand markets - specifically, motor vehicles, machinery, and, to a lesser extent, office equipment. This limits the markets' ability to achieve a critical mass in terms of the number and types of assets that are listed and the volume of transactions that are completed on the portal.
Based on this analysis, there is a need to provide a comprehensive solution that can facilitate trade in multiple types of movable assets. The platform should provide key value-added features that support decisions and bridge institutional weaknesses in the Jamaican market, such as the screening of buyers and sellers, the valuing and viewing of assets, and facilitating online payments. Critical to this approach is the support and collaboration among key stakeholders in the public and private sectors, both in the endorsement and use of the portal. It is hoped that, by addressing these challenges, the portal will be able to facilitate trade among an increasing number of actors (buyers and sellers), as well as a varied number of movable assets. As potential buyers and sellers continue to use the portal, and as confidence in the portal increases, it is hoped that a critical mass in terms of the types of assets listed and the number of transactions on the portal will grow over time.

\subsection{Key Features of the Portal}

\begin{tabular}{|c|c|c|c|c|}
\hline $\begin{array}{l}\text { Registration } \\
\text { of buyers and } \\
\text { sellers }\end{array}$ & $\begin{array}{l}\text { Listing and } \\
\text { valuation of } \\
\text { assets }\end{array}$ & $\begin{array}{l}\text { Real-time } \\
\text { online auction } \\
\text { system }\end{array}$ & $\begin{array}{l}\text { Online } \\
\text { payment } \\
\text { system }\end{array}$ & $\begin{array}{l}\text { Transaction } \\
\text { history and } \\
\text { rating of actors }\end{array}$ \\
\hline
\end{tabular}

1. Supplemented by newspaper ads and advertising among financial institutions 2. Warehousing

3. Robust valuation and supplemented by price guarantees and certification for valued assets 


\subsubsection{Registration of Buyers and Sellers}

The portal should be open only to registered buyers and sellers. Registration will be the first level of screening to ensure that buyers and sellers are legitimately interested.

\subsubsection{Inspection, Listing, and Valuation of Assets}

Specifically, the portal should provide a detailed description of items listed for sale. This can include serial numbers, detailed specifications, and accompanying photos and videos (if required). If necessary, options can also be in place for interested buyers to view items physically at a designated location, such as strategically located warehouses.

The key to successful use of the portal is the valuation of assets. We, therefore, recommend that support be provided by an in-house valuation team whose members are internationally certified to support the valuation of assets listed on the website. This paid-for service can be accompanied by a certification of quality. Other users can have the option to list items "as is," which is not supported by an updated valuation. Accredited valuations can be used to guarantee a baseline payment to creditors.

Given the importance and proliferation of newspaper classified ads in supporting the sale of movable assets, it is recommended that online listing be supplemented with advertisements in local newspapers.

\subsubsection{Developing a Transparent Real-Time Auction System}

It is important to have a transparent real-time auction system that facilitates the sale of assets. The system should display bids for listed assets in real time, highlighting such things as the bid price, the time the bid is placed, and the registration number or user name of the bidder. For security reasons, both buyers and sellers will be identified by their registered user name or ID in order to conceal individual identities. Once bidding is closed and the sale of assets is complete, this information can be saved for a specified period so that it can be viewed by persons querying the bidding process or award of sale.

\subsubsection{Support for Online Payments}

Once transactions are completed, funds can be collected from buyers using common online payment platforms (for example, PayPal) and disbursed to sellers or other key parties. In instances where assets are used as collateral for financing, once the sale transactions are completed, the balance of funding can be distributed directly to the finance companies for settlement of outstanding credit, before final disbursement of any outstanding balances to the seller.

\subsubsection{Maintaining a History of Transactions}

To establish a process for long-term valuation for assets, it is important to capture a history of the completed transactions. Transaction histories and sale prices can be used to generate a reliable value for similarly classified assets.

\subsubsection{Integration to Other Relevant Networks}

Integral to the use of the portal will be linking the portal to key stakeholders, such as finance companies, state agencies, and representative organizations such as MICAF, JMEA, and Jamaica's NSIPPR. Ideally, this portal should be marketed by private companies and state and supporting nongovernmental organizations as the go-to location for disposing and sourcing movable assets.

\subsection{Value Added Services}

\subsubsection{Delivery of Products}

Depending on the nature and weight of assets sold on the portal, we can consider delivery of purchased items to buyers. This service can be provided at an additional cost and facilitated using a local or international package and parcel delivery service.

\subsubsection{Feedback and Rating of Buyers and Sellers}

The portal should have a built-in mechanism to support the provision of feedback on completed transactions, both in terms of the system's ease of use and the rating of buyers and sellers. This information will guide future users to higherquality buyers and sellers.

\subsubsection{Supporting Mechanisms and the Enabling Environment}

The secondary-asset market portal should be managed as a self-funded agency but operated in close collaboration with financial institutions, key state agencies such as RADA, MICAF, NSIPPR, and DBJ, and representative industry organizations such as JMEA, PSOJ, and the Jamaica Agricultural Society (JAS).

A key element of the strategy is the valuation and certification of assets, such as training and certification of valuators in Jamaica. This should be done in collaboration with key internationally accredited valuators such as the International Valuation Council..$^{22}$

Awareness building in the use of movable assets as collateral 
is also critical and has to be an ongoing strategy among borrowers and lenders alike. Results of the primary and secondary research point to a continuing lack of awareness of movable assets as collateral among borrowers in Jamaica; some lenders that utilize movable assets as supplementary collateral may not list these assets on the NSIPPR. Increasing awareness and use of movable assets as collateral can increase the number of listings on the online portal.

Results of the survey of lenders continue to highlight that many borrowers continue to run very informal business operations in Jamaica. A lack of formal financial statements and the unavailability of forecasts hamper the evaluation of credit applications among banks. As such, lenders must increasingly rely on personal relations and past credit history to determine if credit can be provided to lenders.

\subsubsection{Additional Issues}

Results from the survey and interviews with key stakeholders also highlighted the following key issues that need to be considered when implementing the portal solution:

1. A perception by some traders that assets are not valuable once they have been sourced as a reposed item, particularly in the case of motor vehicles. As such, significant discounts (well below the assessed value) may have to be offered to facilitate the disposal of these assets.

2. In terms of equipment, there is a tendency to favor new, rather than used, equipment when making purchases. Additionally, in some instances, owners of equipment may choose not to sell their secondhand assets and may instead keep these assets to use as scrap.

3. A low acceptance of Internet-based transactions by some actors, particularly those from rural communities or locations where Internet connectivity remains limited. One of the key lessons of the launch of ALEX, and also one of the results of our survey, is the strong and continued dominance of informal channels both to source and to dispose of movable assets. Such traditional channels such as newspaper classified ads continue to dominate in the purchase and disposal of movable assets. As such, the portal will have to be used in tandem with these traditional means. It should be emphasized that this online solution can provide faster and more updated information than a traditional paper-based medium.

\subsubsection{Possible Service Providers to Support the Development of the Portal}

Two key service providers that can be used to support the development of the portal solution include i-Naira Integrated Resources Limited, ${ }^{23}$ based in Nigeria, and the online payment provider WIPAY Caribbean ${ }^{24}$ or PayPal. Additionally, a partner for asset valuation can also be considered.

i-Naira Integrated Resources was established in 2011 and has developed an integrated online portal for the listing and disposal of movable assets within an emerging market in Nigeria. Apart from listing and facilitating the disposal of movable assets, i-Naira provides additional value-added services such as valuation of assets, price guarantees to lenders, and collection services. i-Naira also operates closely with the National Collateral Registry of Nigeria to support the deepening of the secondary markets, particularly for collateralized movable assets.

WIPAY Caribbean is an established regional information and communications technology company that facilitates online payment and transactions based on blockchain technologies across various territories in the Caribbean, such as Guyana, St. Lucia, and Trinidad and Tobago. The online payment platform can facilitate the secure transfer of funds between buyers and sellers but can also be integrated with other key stakeholders such as governments, to facilitate the payment of taxes, and financial intermediaries, to facilitate the settlement of outstanding loans.

PayPal is an online payment method that was originally established in 1998. PayPal offers secured online payment transactions for both personal and business accounts. PayPal's seller-protection policy will protect online sales from fraud and chargebacks. Users need to create an account and link their credit-card information to the "PayPal digital wallet." Persons who do not have a credit card or debit card can link their bank account to their PayPal account. Funds can then be transferred from the personal bank account to PayPal accounts. The availability of multiple payment options makes PayPal easy to use and accessible for all users.

The International Valuation Standards Council is an independent global standard setter for the valuation profession. The council's core objectives are to develop highquality International Valuation Standards and to encourage their adoption, along with valuation professionalism provided by professional valuation organizations around the world. The council can be utilized for valuation expertise. 


\subsubsection{Ways That the Portal Addresses Key Requirements for Successful Secondary Markets}

\section{Key Elements for Successful}

Secondary Markets

A critical mass of buyers and sellers

Key income streams and sources

Security, trust, and privacy

Technology

Fulfilling participants' needs

Ensuring creditability and quality

A targeted approach to buyers

\section{How the Solution Addresses This Dimension}

- $\quad$ Being able to facilitate the trade of multiple assets

- Linkages with key stakeholders, such as financial organizations, key state agencies, and representative organizations

- The go-to marketplace to support the disposal of the following secondary assets:

- Public-sector assets

- Insurance companies

- Finance companies

- Note: This may create more competition in this market segment, and there can be potential negative feedback from vested stakeholders.

- Commissions from the sale of the following assets:

- Private assets

- Public assets

- Valuation and certification program

- Advertisements and popups on the portal

- Registration fees

- Value-added:

- Financial and insurance services

- Delivery

- Screening of participants:

- Registration process

- An anonymous bidding system

- Systems to detect shill bidding (collusive and individual)

- Facilitating payments in real time

- Feedback and rating of buyers and sellers

- Anonymous online auction system

- Virtual payment system

- Networked to key agencies (registry, finance companies)

- Disposal of secondary assets

- Screening of buyers and sellers

- Adverse selection (certification of quality, being able to view assets)

- Certification program

- Facilitate physical viewing of listed assets

- The go-to site for movable assets in Jamaica 
CHAPTER 07 


\section{CHAPTER 07}

\section{Conclusion}

Access to capital is one of the fundamental problems plaguing MSMEs (World Bank 2019). This is especially so in emerging and developing countries (Senik et al. 2011). Part of the problem stems from narrow asset bases and MSMEs' inability to conform to traditional lending criteria (especially as they relate to forms of collateral). As such, firms in developing and emerging markets are unable to access much-needed loans that can drive positive economic activity-for instance, product development, innovation, and market-deepening strategies.

This paper has examined the wider framework of MABL and highlighted the importance of developing deep secondary markets to support the implementation of MABL. Based on the review, to establish secondary markets it is important to have a critical mass of buyers and sellers willing to trade. It is also important to build trust and confidence in these markets. This can be done by ensuring timely completion of transactions and ensuring the security and privacy of actors. It is also important to develop various income sources through commissions and fees to facilitate the ongoing maintenance costs of these markets. Furthermore, transactions on secondary markets are increasingly facilitated through web-based solutions and technology. In some instance, secondary markets can be very specialized, focused on a specific niche of customers or type of movable asset. Many new online marketplaces also offer value-added services, such as the valuation of assets, insurance, and financing services, supporting both buyers and sellers throughout the transaction process while also acting as a one-stop shop for related services.

Lending based on movable assets has been on the rise in Jamaica, but motor vehicles make up the bulk (more than 75 percent) of assets listed on the registry, and lending is geared primarily toward consumers (more than 63 percent), rather than commercial interests. Collectively, this reflects a somewhat skewed and limited usage of lending based on movable assets in Jamaica.
A deeper examination of secondary markets in Jamaica based on interviews as well as a survey of borrowers and lenders paints a picture of a very fragmented and still very much emerging market system. Newspaper classified ads continue to dominate as the primary means to facilitate the sourcing, valuation, and disposal of movable assets. Also important are informal network relationships both within and outside of representative organizations to support these transactions. Online markets solutions also exist in Jamaica, but most provide very limited support, apart from the listing of assets and bringing buyers and sellers together. A fundamental issue in the Jamaican context is the valuation of assets. As such, both buyers and sellers use innovative means to facilitate the valuation process, such as online tools, newspaper classified ads, personal experience, and word-of-mouth relationships. This therefore limits the types of assets frequently traded in the secondary market of Jamaica. Specifically, motor vehicles, machinery, and office equipment continue to be the most frequently traded assets in Jamaica. Other movable assets such as inventory, crops, and intellectual property rights are traded less frequently.

The recommendation is therefore to establish a single online platform that can facilitate the trade of multiple types of movable assets and bring a critical mass of buyers and sellers from Jamaica and the wider Caribbean region to facilitate a greater level of trade in movable assets. More importantly, the online platform should be built with specific value-added services that facilitate such transactions as valuation of assets, facilitation of online payments, and delivery services. To build usage at least initially, use of the platform should be complemented with traditional market channels, such as newspaper advertisement and classified ads. It is important that the promotion and use of the portal be facilitated through key stakeholder organizations such as MICAF, RADA, DBJ, JMEA, PSOJ, and JAS as well as key financial institutions. The portal should be the go-to location for sourcing and disposing movable assets. It is hoped that as usage of the portal increases over time, historical information can be used to build a repository of data on transactions involving movable assets and further deepen information on transactions in these regional markets. 


\section{Appendix A: Detailed Stakeholder Mapping}

Stakeholder

1 Ministry of Industry, Commerce, Agriculture and Fisheries, Jamaica

2 Development Bank of Jamaica

3

PSOJ Access to Finance Panel

4

Jamaica Intellectual Property Office

JIPO

5 Companies Office of Jamaica

COJ

JC

PIOJ

JBDC

8 Jamaica Business Development

Corporation

$9 \quad$ Bank of Jamaica

10

11 Jamaica National Small Business Loans

12 Jamaica Cooperative Credit Union League

13 Jamaica Bankers Association

14 National Export-Import Bank of Jamaica

PSOJ

JSE

JBA

\section{Stakeholder Role}

Overview of movable assets financing and identification of players within the applicable sector

DBJ Regulatory oversight and legislative details for secured transactions, credit access, and loan guidelines

Practical insights and detail on relevant issues affecting access to financing for small and medium enterprises and entrepreneurial sectors

Determine other potential approved types of movable assets

Demonstration of SIPPR applications and use Identification of other critical players, including new or expanded platform(s), for trading movable assets

Extrajudicial enforcement of collateral assets

Prioritization of policies

Provide feedback on market reach and areas for expansion

Access to innovation programs, including accelerators and incubators, for the development of Fintech applications for an electronic platform(s)

BOJ Regulatory oversight and legislative details for secured transactions, credit access, and loan guidelines

Framework for secondary market activities

JNSBL Direct engagement for focus groups, survey participants, and one-on-one discussions for the creation of new credit products

JCCUL Identification of key members and regulatory requirements

Direct feedback on desired requirements (legislative, scale, risk mitigants) that would drive engagement and participation in movable assets financing. Individual banks' creation of new credit products

Direct engagement through focus groups, survey participants, and one-on-one discussions for the creation of new credit products 
Crucial class of financiers for small and medium enterprises, micro, and individuals

Direct engagement through focus groups, survey participants and one-on-one discussions for business models structuring

16 National Peoples Cooperative Bank

17 Jamaica Association of Micro Financing

18 CRIF Jamaica

19 CreditInfo Jamaica

20 Department of Cooperatives and Friendly Societies

21 Small Business Association of Jamaica/MSME Alliance

22 Private Sector Organization of Jamaica

23 Jamaica Manufacturers and Exporters Association

24 Jamaica Agricultural Society

25 Women Entrepreneurs Network of the WENC Caribbean

26 Young Entrepreneurs Association

27 Jamaica Chamber of Commerce
NPCB

JAMFIN

CREDIT BUREAU

CREDIT BUREAU

DCFS

SBAJ

PSOJ

JMEA

JAS

YEA

JCC
Direct engagement for focus groups, survey participants, and one-on-one discussions for the creation of new credit products

Direct engagement through focus groups, survey participants, and one-on-one discussions for business models structuring

Analysis of credit reporting and enforcement system

Analysis of credit reporting and enforcement system

Legislative/regulatory conditions and the ability for cooperatives in the movable asset space

Core membership engagement for survey and focusgroup sessions

Ground-level policy recommendations and implementation

Core membership engagement for survey and focusgroup sessions

Core membership engagement for survey and focusgroup sessions

Membership engagement for survey and focus-group sessions

Membership engagement for survey and focus-group sessions

Provide a sample mix of potential secured creditors and debtors 


\section{End Notes}

- Alvarez de la Campa, A. 2011. Increasing Access to Credit through Reforming Secured Transactions in the MENA Region. Washington, DC: World Bank Group.

- Alvarez de la Campa, A., S. C. Downes, and B. T. Hennig. 2012. Making Security Interests Public: Registration Mechanisms in 35 Jurisdictions. Washington, DC: World Bank Group.

- $\quad$ Alvarez de la Campa, A., E. T. Wohlers, Y. Baranes, and S. Simavi. 2010. Secured Transactions Systems and Collateral Registries. Washington, DC: International Finance Corporation.

- Balocco, R., A. Perego, and S. Perotti. 2010. "B2B eMarketplaces: A Classification Framework to Analyse Business Models and Critical Success Factors." Industrial Management and Data Systems 110 (8): 1117-37.

- Brunn, P., M. Jensen, and J. Skovgaard. 2002. "e-Marketplaces: Crafting a Winning Strategy." European Management Journal 20 (3): 286-98.

- CAK (Competition Authority of Kenya). 2019. "Market Inquiry to the SME Leasing Sector of Kenya."

- Calomiris, C. W., M. Larrain, J. Liberti, and J. Sturgess. 2017. "How Collateral Laws Shape Lending and Sectoral Activity." Journal of Financial Economics 123 (1): 163-88.

- Fleisig, H., M. Safavian, and N. de la Pena. 2006. Reforming Collateral Laws to Expand Access to Finance. Washington, DC: World Bank Group.

- Gallaugher, J. M., P. Auger, and A. BarNir. 2001. "Revenue Streams and Digital Content Providers: An Empirical Investigation." Information and Management 38 (7): 473-85.

- IFC (International Finance Corporation). 2017. MSME Finance Gap: Assessment of the Shortfalls and Opportunities in Financing Micro, Small, and Medium Enterprises in Emerging Markets. Washington, DC: International Finance Corporation. https://openknowledge.worldbank.org/handle/10986/28881 License: CC BY-NC-ND 3.0 IGO.

- Love, I., M. S. M. Pería, and S. Singh. 2016. "Collateral Registries for Movable Assets: Does Their Introduction Spur Firms' Access to Bank Financing?" Journal of Financial Services Research 49 (1): 1-37.

- Senik, Z. C., B. Scott-Ladd, L. Entrekin, and K. A. Adham. 2011. "Networking and Internationalization of SMEs in Emerging Economies." Journal of International Entrepreneurship 9 (4): 259-81.

- Senior, A. 2012. "Financing the Micro, Small and Medium Enterprises (MSMEs) Sector in Jamaica: Constraints and Prospects for Leasing, Factoring and Microfinance." Bank of Jamaica. http://boj.org.jm/uploads/pdf/papers_pamphlets/ papers_pamphlets_Financiang_the_MSME_Sector_in_Jamaica_-_Constraints_and_Prospects_for_Leasing, Factoring_and_Microfinance.pdf.

- Stockdale, R., and C. Standing. 2003. "Market Makers' Recognition of Key Success Factors in Electronic Marketplaces." Australasian Journal of Information Systems 10 (2): 23-37.

- Sultanov, M., J. M. Wilson, E. MacEachern, L. M. Salamina, and P. Chhabra. 2019. Secured Transactions, Collateral Registries and Movable Asset-Based Financing (English). Knowledge Guide. Washington, DC: World Bank Group.

- Torero, M., M. Robles, M. Hernández, J. De la Roca, M. Webber, and D. Thomas. 2006. The Informal Sector in Jamaica. Economic and Sector Studies No. RE3-06-010. Inter-American Development Bank.

- Wise, R., and D. Morrison. 2000. "Beyond the Exchange: The Future of B2B." Harvard Business Review 78 (6): 86-96.

- World Bank. 2019. "Small and Medium Enterprises (SMEs) Finance: Improving SMEs' Access to Finance and Finding Innovative Solutions to Unlock Sources of Capital" (web page). https://www.worldbank.org/en/topic/smefinance. 


\section{References}

1. Assessment of Leasing and Factoring Market in Jamaica, Development Bank of Jamaica (DBJ); see http://www.boj.org.jm/pdf/NFIS_Annual_Report_2017.pdf.

2. http://www.jamaicaobserver.com/news/IMF-points-finger-at-banks-for-lack-of-growth_62122

3. Quartile 4 is the most constrained and represents greater challenges in terms of access to finance among borrowers drawn from manufacturers, including agro-processors operating in Jamaica.

4. An example of this is the case of Trinidad and Tobago, where supporting regulations surrounding the facilitation of online payments have yet to pass, hampering the usage of e-payments locally.

5. See the Summary of Provisions related to the Registry for the Security Interests in Personal Property.

6. The two credit bureaus in Jamaica are CRIF Information Bureau Jamaica and Credit info Jamaica.

7. See Access to Finance for MSMEs and Housing, World Bank, 2017: http://documents.worldbank.org/curated/ en/598931517454038216/Jamaica-Access-to-Finance-for-Micro-Small-and-Medium-Enterprises-Project.

8. "Operational Review of Secured Transaction Regime in Jamaica," MICAF, 2017.

9. Approximately 6 percent of the respondents utilized auctions also to dispose of motor vehicles.

10. Interestingly, this pattern was also found in borrowers' decision to dispose of equipment and machinery, where only 25 percent of survey respondents indicated that they chose to dispose of these assets by sale. Approximately, 45 percent of respondents indicated that they would keep these assets so that they could be used for spare parts.

11. Lenders in focus groups did not specify if these applications were existing or new businesses. In the survey, however, many of the lenders continued to highlight the overall informality with which many businesses continued to operate in Jamaica, as will be the case for many other emerging markets.

12. Source: World Health Organization/European Centre for Disease and Control.

13. COVID-19: The CIDRAP Viewpoint, CIDRAP, April 30, 2020.

14. The Economist, May 2, 2020.

15. The U.S. Labor Market during the Beginning of the Pandemic Recession, Becker Freidman Institute, June 2020.

16. https://qz.com/1853641/covid-19-job-losses-in-april-hurt-women-and-minorities-the-most/

17. In Hokkaido, like Jamaica, tourism is an important industry.

18. "Japanese Island Suffering Second Wave of Coronavirus after Lifting Lockdown Too Early," The Telegraph, April 29, 2020.

19. "Wuhan Shows the World that the End of Lockdown Is Just the Beginning of the Covid-19 Crisis," CNN, April 30, 2020.

20. "Caribbean Digitally Unprepared for Covid-19," Barbados Advocate, March 31, 2020.

21. Appendix A summarizes all features of the main secondary-market platforms in use in Jamaica today.

22. https://www.ivsc.org/about

23. https://i-naira.com/

24. https://wipaycaribbean.com/what-is-wipay/

25. https://www.ivsc.org/ 



\begin{tabular}{l|l} 
International \\
Finance Corporation \\
worLd BANK GROUP
\end{tabular} 